\title{
Bioaccumulation of persistent organic pollutants in female common dolphins (Delphinus delphis) and harbour porpoises (Phocoena phocoena) from western European seas: Geographical trends, causal factors and effects on reproduction and mortality
}

G.J. Pierce ${ }^{\mathbf{a}, \mathbf{b},{ }^{*}, \text { M.B. Santos }}{ }^{\mathbf{a}, \mathbf{b}}$, S. Murphy ${ }^{\mathbf{c}, \mathbf{d}}$, J.A. Learmonth ${ }^{\mathbf{a}}$, A.F. Zuur ${ }^{\mathrm{e}}$, E. Rogan ${ }^{\mathrm{c}}$, P. Bustamante $^{f}$, F. Caurant ${ }^{f}$, V. Lahaye ${ }^{\mathrm{a}, \mathrm{f}}$, V. Ridoux ${ }^{\mathrm{f}}$, B.N. Zegers ${ }^{\mathrm{g}}$, A. Mets $^{\mathrm{g}}$, M. Addink ${ }^{\mathrm{h}}, \mathrm{C}$. Smeenk $^{\text {h }}$, T. Jauniaux', R.J. Law', W. Dabink ${ }^{\mathrm{k}}$, A. López', J.M. Alonso Farré', A.F. González ${ }^{\mathrm{m}}$, A. Guerra ${ }^{m}$, M. García-Hartmann ${ }^{\text {g, n }}$, R.J. Reid ${ }^{\circ}$, C.F. Moffat ${ }^{p}$, C. Lockyer ${ }^{q}$ and J.P. Boon ${ }^{g}$

\footnotetext{
a School of Biological Sciences, University of Aberdeen, Tillydrone Avenue, Aberdeen AB24 2TZ, UK

${ }^{b}$ Instituto Español de Oceanografía, Centro Oceanográfico de Vigo, P.O. Box 1552, 36200, Vigo, Spain

c AFDC, Department of Zoology, Ecology and Plant Science, University College, National University of Ireland, Enterprise Centre, North Mall, Cork, Ireland

Sea Mammal Research Unit, Gatty Marine Laboratory, University of St. Andrews, St. Andrews, Fife KY16 8LB, UK

e Highland Statistics, 6 Laverock Road, Newburgh, Aberdeenshire AB41 6FN, UK

${ }^{f}$ Centre de Recherche sur les Ecosystèmes Littoraux Anthropisés, UMR 6217 CNRS-IFREMER-Université de la Rochelle, 22 avenue Michel Crépeau, 17042 La Rochelle, France

${ }^{9}$ Royal Netherlands Institute for Sea Research (NIOZ), P.O. Box 59, 1790 AB Den Burg, Texel, The Netherlands

${ }^{\mathrm{h}}$ National Museum of Natural History, P.O. Box 9517, 2300 RA Leiden, The Netherlands

'Department of Pathology, University of Liege, Liege, Belgium

${ }^{j}$ Cefas, Remembrance Avenue, Burnham-on-Crouch, Essex CM0 8HA, UK

${ }^{k}$ Centre de Recherche sur les Mammifères Marins, Port des Minimes, Avenue Lazaret, 17000 La Rochelle, France

' CEMMA, Apdo. 15, 36380 Gondomar, Pontevedra, Spain

${ }^{m}$ Instituto de Investigaciones Marinas (C.S.I.C), Eduardo Cabello 6, 36208 Vigo, Spain

${ }^{n}$ Elephant house, Muelheimer Str. 273, 47058 Duisburg, Germany

${ }^{\circ}$ SAC Veterinary Science Division, Drummondhill, Stratherrick Road, Inverness IV2 4JZ, UK

${ }^{\mathrm{p}}$ FRS Marine Laboratory, 375 Victoria Road, Aberdeen AB11 9DB, UK

${ }^{q}$ Age Dynamics, c/o Heggåsvegen 7, N-9020 Tromsdalen, Norway
}

*: Corresponding author: G.J. Pierce, Tel.: +44 1224 273255; fax: +44 1224 272396, email address : g.j.pierce@abdn.ac.uk

\begin{abstract}
:
Concentrations of polychlorinated biphenyls (PCBs) in blubber of female common dolphins and harbour porpoises from the Atlantic coast of Europe were frequently above the threshold at which effects on reproduction could be expected, in $40 \%$ and $47 \%$ of cases respectively. This rose to $74 \%$ for porpoises from the southern North Sea. PCB concentrations were also high in southern North Sea fish. The average pregnancy rate recorded in porpoises $(42 \%)$ in the study area was lower than in the western Atlantic but that in common dolphins (25\%) was similar to that of the western Atlantic population. Porpoises that died from disease or parasitic infection had higher concentrations of persistent organic pollutants (POPs) than animals dying from other causes. Few of the common dolphins sampled had died from disease or parasitic infection. POP profiles in common dolphin blubber were related to individual feeding history while those in porpoises were more strongly related to condition.
\end{abstract}

High PCB levels were recorded in porpoises and common dolphins from European coasts.

Keywords: Phocoena phocoena; Delphinus delphis; Persistent organic pollutants; Reproduction; Diet 


\section{Introduction}

Long-lived apex predators are particularly at risk from effects of persistent organic pollutants (POPs), e.g. polychlorinated biphenyls (PCBs) and dichlorodiphenylethanes (e.g. DDT), due to bioaccumulation (increasing concentration with age in individuals) and biomagnification (higher levels higher up the food chain, especially when moving from gill-breathing animals like fish and cephalopods to air-breathing animals like marine mammals). POPs are lipophilic compounds that tend to accumulate in the lipid-rich blubber (although lipidnormalized concentrations of POPs in different body compartments tend to be very similar). In marine mammals, POPs enter the body almost exclusively through the diet.

Amounts of POPs in marine mammal tissues will vary in relation to input (reflecting levels of environmental contamination, trophic position and the type of prey eaten), elimination in faeces, transformation to non-toxic forms and, in the case of lipophilic organic compounds, transfer from mother to offspring during pregnancy and lactation. Aguilar et al. (1999) reviewed the main biological factors responsible for variation in pollutant 
concentrations in cetaceans, highlighting the importance of diet, body size (which affects excretion rate, activity of detoxifying enzymes and metabolic rate), body composition (especially, in the case of lipophilic POPs, the mass of blubber), nutritive condition, disease, age, sex, and duration of lactation.

The harmful consequences of bioaccumulation of POPs in marine mammals include depression of the immune system (e.g. de Swart, 1995; Ross, 1995), increased risk of infection (Hall et al., 2006) and reproductive failure (Helle et al., 1976; Reijnders, 1986), potentially adversely affecting population status (Reijnders, 1984). Reijnders (1986) showed that reproductive failure in harbour seals (Phoca vitulina) was linked to feeding on contaminated fish: seals fed on fish from the Wadden Sea showed a decreased reproductive rate at an average total-PCB level of 25-27 $\mu \mathrm{g} \mathrm{g}^{-1}$ lipid, whereas a control group showed normal reproductive rates at mean PCB levels of 5-11 ug g ${ }^{-1}$ lipid. However, Addison (1989) argued that reproductive failure in several wild marine mammal populations could not be conclusively attributed to effects of contaminants. Jepson et al. (2005) found that total PCB levels in porpoises from UK waters were significantly higher in animals that had died from infectious diseases than in those dying as a result of physical trauma. They suggested that these results supported a causal (immunotoxic) relationship between PCB exposure and infectious disease mortality. De Guise et al. (1995) report evidence of immunosuppression related to organochlorine bioaccumulation in belugas (Delphinapterus leucus) in the Gulf of St Lawrence.

Not all POPs that are present in food find their way equally into blubber. For example, within the PCBs, some are subject to enzyme-mediated metabolism, related to their structural characteristics, and bioaccumulate to a much lesser degree than the persistent congeners. Certain chlorinated biphenyls can be metabolised by cytochrome P-450. Although the ability to metabolise PCBs was previously thought to be less well developed in cetaceans than in pinnipeds (Boon et al., 1997), implying that cetaceans may be more sensitive to effects of exposure to POPs, more recent evidence (reviewed by Hall et al., 2006) suggests that this may not be the case. Immuno-reactive proteins recognised by heterologous CYP2B antibodies are present in several cetaceans including harbour porpoises (White et al., 1994; Goksøyr, 1995; Hummert et al., 1995) and CYP1B-like amino acid sequences are present in striped dolphin cDNA (Godard et al. 2000).

Even though use of some harmful organic compounds has decreased or even ceased as the associated dangers have become recognised, new classes of chemicals are of concern, 
notably the brominated flame retardants (de Boer et al., 1998). Initially, studies focussed on the brominated diphenyl ether formulations (PBDEs). Their acute toxicity is low, but critical sub-lethal effects include neurodevelopmental toxicity and altered thyroid hormone homeostasis, but further studies are needed (Darnerud, 2003). The production and use of the penta- and octa-mix PBDE formulations was banned in the EU in 2004.

Recently, attention has focused on hexabromocyclododecane (HBCD), which is the principal brominated flame retardant in polystyrene foams used in the building industry (Law et al., 2005, 2006a). With a worldwide production of 16700 tons in 2001, of which the majority (9500 tons) was used in the European market, it is recognised as a priority pollutant by the European Union. Retrospective analyses of eggs of the guillemot (Uria aalge) from the Baltic Sea demonstrated that HBCD residues were already detectable in the early 1970s, although levels started to increase sharply after 1980 (Sellström et al., 2003). A recent study has shown rising concentrations from 2001 to 2003 in blubber of harbour porpoises from the UK (Law et al., 2006b).

Toxic elements such as cadmium (Cd) and mercury (Hg) are also known to bioaccumulate in the tissues of marine mammals. Again, this will reflect diet: for example, species that feed primarily on cephalopods may be expected to accumulate higher levels of cadmium than those feeding on fish (Bustamante et al., 1998, Lahaye et al. 2005). Another element of interest is zinc ( $\mathrm{Zn})$, which plays an important role in mammalian immune systems. High concentrations of $\mathrm{Zn}$ in the liver have previously been associated with poor health in harbour porpoises (Das et al., 2004) and in humans (e.g. Amdur et al., 1991) and may thus provide an index of health status.

The links between feeding, reproduction, condition and contaminant burdens in marine mammals are undoubtedly complex. Important insights have been provided from studies on populations in which individual reproductive history is known (e.g. bottlenose dolphins in Sarasota Bay, Wells et al., 2005) but there have been no experimental studies on captive cetaceans comparable to the work on seals undertaken by Reijnders (1986). For a large-scale survey, the use of stranded animals has several advantages over taking biopsies from living animals in the wild. Sampling from dead animals is less expensive, raises no ethical issues, and provides access to all tissues, not simply blubber, as well as a wealth of ancillary information on size, age, reproductive status, condition and pathology. Restricting sampling to relatively fresh carcasses can assure high sample quality, while analysis of the ancillary data can assist in interpretation of contaminant data, including helping to control for possible biases associated with such opportunistic sampling. 
The aim of the present study was to survey geographical variation in concentrations

144 of persistent organic contaminants in body tissues of small cetaceans in European Atlantic waters, specifically two of the most commonly occurring species, common dolphin

146 Delphinus delphis and harbour porpoise Phocoena phocoena, and to identify biological 147 factors (e.g. diet) responsible for observed patterns of variation in concentrations. The 148 patterns of bioaccumulation in female marine mammals are more complex than those in 149 males due to the transfer of POPs to the offspring during pregnancy and lactation. However, 150 the consequences for reproductive output are more readily observed in females and are, 151 arguably, much more important at the population level. We therefore focused on females. 152 In modelling regional variation in concentrations of the main categories of POPs in 153 the two cetacean species, we controlled for effects of individual length, age, reproductive 154 status, and condition. We used blubber thickness as an indicator of condition. Since blubber 155 thickness varies seasonally in cetaceans (Elsner, 1999; Lockyer et al., 2003; Learmonth, 156 2006), we included season as an additional explanatory variable, so that any marginal effect 157 of blubber thickness should be related to condition.

158 We tested whether POP concentrations were related to diet (as proxied by fatty acid 159 profiles in the inner blubber layer) and analysed variation in POP levels in samples from a 160 range of putative prey species. We tested for a link between POP and trace element (Hg, Cd) 161 concentrations in tissues.

162 Finally we examined evidence of possible consequences of POP bioaccumulation for 163 reproductive output and health. We tested whether the incidence of pregnancy was related to 164 POP concentrations. Regional variation in POP concentrations in the two cetacean species is 165 also summarised and interpreted in relation to data on average pregnancy rate. We tested whether Zn levels in the liver can provide an indicator of health status (as suggested by Das et al., 2004) and whether POP concentrations were related to cause of death and/or liver Zn

168 concentrations.

169

\section{Methods}

\subsection{Sampling programme}


176 French and Galician (NW Spain) Atlantic coasts (see Figure 1). In Ireland, the sample 177 included a substantial proportion of fishery by-catches. Priority was given to females 178 recovered in good condition, from which all necessary samples could be obtained, but data 179 and samples were collected from other animals when possible. Samples obtained from France 180 included those originating from a mass live stranding that occurred in February 2002 at 181 Pleubian, Brittany. The nursery group comprised adult (7+ years old) females accompanied 182 by their unweaned calves. Of 53 individuals found dead, 52 were fully necropsied.

183 Data collection protocols followed European Cetacean Society guidelines for gross 184 post-mortem examination and tissue sampling (Kuiken and Hartmann, 1991). Basic data 185 collected from each animal included stranding location, date, species, sex, total length and 186 blubber thickness (measured immediately in front of the dorsal fin in dorsal, midline and 187 ventral positions). Animals sampled ranged in decomposition state from extremely fresh 188 (point 2a on the ECS scale) to moderately decomposed (point 3). Pathological and 189 histopathological analyses were routinely carried out in Scotland, Netherlands, Belgium and 190 Galicia. Pathological and histopathological analyses were also carried out for some samples 191 from France and Ireland. Infectious disease mortality is generally regarded as a consequence 192 rather than a cause of high contaminant burdens (see Jepson et al., 2005).

Blubber samples for POP analysis were taken from the left side in front of the dorsal 194 fin. Samples were complete vertical cross-sections, to prevent any possible effects of 195 stratification of the blubber. An additional (adjacent) blubber sample was collected for fatty 196 acid analysis. Samples of liver and kidney, for trace element analysis, were removed and 197 stored in polythene bags. All samples for pollutant analysis were frozen at $-20^{\circ} \mathrm{C}$ until 198 required for analysis. During transport, samples were packed in insulation boxes with dry ice 199 to ensure that they remained frozen.

At least 5 teeth were collected from each sampled individual, selecting the least worn/damaged and least curved teeth, to ensure sufficient material for replicate preparations. Teeth were preserved frozen or in $70 \%$ alcohol. The ovaries and associated reproductive tract were collected and preserved in 10\% neutral formalin. The uterus was examined for presence of a foetus. Milk glands were examined for evidence of lactation.

207 This sampling made use of fish and squid collected during trawling surveys, as well as 208 market sampling, or material collected for other projects. Selection of species was based on 209 identification of the main prey species from the literature (Santos \& Pierce, 2003, Santos et 
al., 2004a,b, 2005; De Pierrepont et al., 2005; Pusineri et al., 2006) and unpublished data

211 held by the authors, although minor prey species were also included where material was

212 available. Variation in contaminant concentrations in prey tissues was analysed in relation to

213 taxonomic group, geographical location and body size.

\subsection{POP measurements}

Because POP analysis was budget-limited, effort was focused on the best sample sets

218 (i.e. 20+ individuals per region per species), concentrating on those females for which most data were available on other variables. Thus, for porpoises, analysis focused on samples from Ireland, Scotland, and the southern North Sea (Netherlands, Belgium and northern France). For common dolphins, analysis focused on samples from Ireland, France and Galicia. POPs measurements were made on 70 female common dolphins and 67 female porpoises (out of 531 common dolphins and 243 porpoises collected, the latter figures including individuals both sexes and all decomposition states). During the sampling programme, additional funding became available to measure levels of HBCD in some of the samples (see Zegers et al., 2005, for further details).

Analysis of POP concentrations in cetacean and prey samples was carried out at the Royal Netherlands Institute for Sea Research (NIOZ), with some Scottish cetacean samples analysed at the Centre for Environment, Fisheries and Aquaculture Science (Cefas). For prey samples, analysis was normally carried out on homogenates of whole animals. For small species, samples from several individuals sometimes had to be combined. The samples were thawed and homogenised, extracted with a mixture of pentane: dichloromethane: water and lipid content determined gravimetrically. Samples were cleaned by sulphuric acid treatment and elution over silica columns to separate the contaminants of interest from the lipids used.

Organochlorines were determined by gas chromatography with electron capture

237 Since concentrations of many compounds were often below the limit of detection, we finally 238 selected eighteen PCB congeners for further analysis (CB28, CB49, CB52, CB99, CB101, 239 CB118, CB128, CB138; CB141, CB149, CB151, CB153, CB170, CB177, CB180, CB183, 240 CB187 and CB194). Data available from Cefas (for Scottish porpoises) excluded values for 241 CB99 and CB177, which were therefore dropped from the majority of the analyses of data 242 for porpoises. Other OCs analysed were $p, p$ '-DDE, which is the most persistent metabolite 243 and the major representative of the insecticide DDT-group, the fungicide hexachlorobenzene 
244 (HCB), and pentachlorobenzene (PeCBz), a fire retardant and precursor for the fungicide 245 pentachloronitrobenzene.

$246 \quad$ Based on results of studies on mink, otters and seals, a $\Sigma$-PCB level of $17 \mu \mathrm{g} \mathrm{g}^{-1}$ lipid

247 in blubber has been estimated as the threshold level for effects on reproduction in aquatic

248 mammals (Kannan et al., 2000) and this value was previously applied in a study of

249 bottlenose dolphins by Schwacke et al. (2002). For comparison with this figure, which was

250 based on the commercial PCB mixture Aroclor 1254, we also derived the "ICES7" value (the 251 sum of concentrations of CB28, CB52, CB101, CB118, CB138, CB153, CB180), since three 252 times this value is equivalent to the Aroclor 1254 value (Jepson et al., 2005).

253 Brominated flame retardants were determined by gas chromatography with electron254 capture negative ion mass spectrometry (GC-ECNIMS). The compounds were detected on 255 the basis of selective ion recording at the masses of the two bromine isotopes with masses 79 256 and 81, which occur in the environment in approximately a 1:1 ratio. Our external standard 257 mixture for the polybrominated diphenyl ethers (PBDEs) contained 11 PBDE congeners and 258 HBCD. Since many compounds were often below their limit of detection, we finally selected 259 five PBDE congeners (BDE47, BDE99, BDE100, BDE153 and BDE154) for further 260 analysis. For the determination of total ( $\alpha-, \beta$-, and $\gamma-$ ) hexabromocyclododecanes (HBCDs) 261 at NIOZ, elution of the silica column was performed with $30 \mathrm{ml}$ of an 85\% pentane : 15\% 262 diethyl ether mixture, an alteration required particularly for measurement of the $\beta$-isomer 263 (Boon et al., 2002; Zegers et al., 2003). Cefas conducted analyses for HBCD on an 264 individual diastereoisomer basis using LC-MS (Law et al., 2006b). Funding for HBCD 265 analysis did not become available until after sample processing was underway and sample 266 sizes are therefore smaller. Consequently HBCD data are not included in all analyses. 267 At regular intervals, certified reference materials were analysed for PCBs and DDE 268 and laboratory reference materials were analysed for PBDEs (since certified reference 269 materials were not at the time available for this class of compounds). The values obtained fell 270 within the accepted normal ranges. Both NIOZ and Cefas participated in tests of analytical 271 protocols in which both laboratories performed up to the current standard. Results from 272 duplicate samples from the same animals analysed by both laboratories were similar. 
Kidney and liver samples were freeze-dried and then ground to powder. Total Hg in liver was directly determined using a mercury analyser AMA 254. Prior to renal Cd and hepatic $\mathrm{Zn}$ analyses, two aliquots of approximately 200mg of each homogenised dry sample were digested with $3.5 \mathrm{ml}$ of $65 \% \mathrm{HNO}_{3}$ at $60^{\circ} \mathrm{C}$ for 3 days. $\mathrm{Cd}$ and $\mathrm{Zn}$ were analysed by Atomic Absorption Spectrometry (AAS) using flame (Varian spectrophotometer Vectra 250 Plus with deuterium background correction). Graphite furnace (Hitachi Z5000 with Zeeman correction) was also used when low Cd levels were detected in samples.

Organic Hg in the liver is normally detoxified through demethylation by selenium

284 (Se), and conversion to tiemannite (Martoja \& Berry, 1980). Thus the Hg:Se ratio may provide an indicator of the extent to which $\mathrm{Hg}$ has been successfully detoxified. Since the atomic masses of $\mathrm{Hg}$ and Se are 200.59 g. $\mathrm{mol}^{-1}$ and 78.96 g.mol${ }^{-1}$ respectively, when concentrations of both elements are expressed as $\mu \mathrm{g} . \mathrm{g}^{-1}$ wet weight, ratios greater than approximately 2.5 suggest the presence of toxic Hg. Determination of Se in liver was carried out by graphite furnace AAS (Hitachi Z5000 with Zeeman correction).

Quality controls were ensured by analysis of reference materials (TORT-2, DOLT-2 and 3) from the Canadian National Research Council (CNRC). Concentrations of Hg, Cd, Se and Zn were expressed in $\mu \mathrm{g} / \mathrm{g}$ wet weight.

\subsection{Determination of age and reproductive status}

Age was determined by analysing growth layer groups (GLGs) in the dentine of teeth, following the methods of Hohn and Lockyer (1995) and Lockyer (1995). Teeth were decalcified and sectioned using a freezing microtome. The most central and complete sections (including the whole pulp cavity) were selected from each tooth, stained, mounted on glass slides, and allowed to dry. GLGs were counted under a binocular microscope and on enhanced computer images of the sections. All readings were initially made blind (with no access to other data on the animals) and replicate counts were made by at least two readers. As ages were recorded by a number of different researchers, cross-calibration exercises were carried out under the direction of ER and CL.

Methods for examining and assessing female reproductive status are described in Murphy (2004) and Learmonth (2006). The ovaries were rinsed in water for 24 hours and transferred to $70 \%$ ethanol. For each ovary the maximum length, height, width ( $\mathrm{mm})$ and weight (g) were recorded. Both ovaries were examined externally to record the presence of a corpus luteum (CL) of pregnancy and corpora albicantia (CA) of ovulation. Ovaries were 
hand sectioned into 0.5-2mm slices and examined internally under binocular microscope for

311 the presence of additional corpora albicantia and follicles. Females were normally

312 considered sexually mature if the ovaries contained at least one corpus luteum or albicans.

313 An overall pregnancy rate was derived for each species in each region based on animals

314 sampled during the present study. We also compare these results to the best estimates of

315 pregnancy rate available from wider sampling.

316 Pregnancy was established by the presence of an embryo/foetus. It is difficult to be

317 certain whether a corpus luteum is associated with a pregnancy, e.g. one will be present even

318 if the pregnancy was lost to an early miscarriage. In common dolphins there was good

319 agreement in the final data set (animals for which POPs data were available) between

320 presence of foetuses (11 instances) and of a corpus luteum (12 instances). In the final harbour

321 porpoise data set there were only 6 females carrying foetuses and 11 with a corpus luteum

322 and the latter variable was selected for use in analysis as it resulted in a less unbalanced data

323 set.

\subsection{Determination of fatty acid profiles}

Fatty acid data were considered to be a more reliable indicator of average individual diet than stomach contents, since many stomachs were empty and food remains in the stomach normally represent a single meal whereas fatty acids in blubber represent dietary input integrated over a time-scale of weeks to months. The inner layer from each blubber sample, which is more metabolically active than the outer layer and contains higher levels of fatty acids derived primarily from the diet (Koopman et al., 1996), was analysed for fatty acids. Lipids were extracted from blubber samples (approximately $1 \mathrm{~g}$ ) and homogenised whole fish samples (approximately 10g) using the method of Bligh and Dyer (1959) as modified by Hanson and Olley (1963). Fatty acid methyl esters (FAMEs) were prepared by acid catalysis and analysed by gas chromatography with flame ionisation detection (GCFID). Further details on the methods for determining fatty acid profiles are described in Learmonth (2006). standards. The normalised area percentage (NA\%) was calculated for 31 fatty acids: 12:0, 341 14:0, 14:1n-5, 15:0, 16:0, 16:1n-7, 16:2n-6, 16:3n-6, 16:4n-3, 18:0, 18:1n-9, 18:1n-7, 18:2n-

342 6, 18:3n-6, 18:3n-3, 18:4n-3, 20:0, 20:1n-11, 20:1n-9, 20:2n-6, 20:4n-6, 20:3n-3, 20:4n-3, $343 \quad 20: 5 n-3,22: 0,22: 1 n-11,22: 1 n-9,21: 5 n-3,22: 5 n-3,22: 6 n-3$ and 24:1n-9. 
Since it was impractical to continue analysis with 31 explanatory variables related to diet, fatty acid variation was summarised using PCA. For common dolphin data, the first two PCA axes explained $28.6 \%$ and $18.7 \%$ of variation, respectively, in fatty acid profiles. Axis 1 scores related most strongly to relative amounts of fatty acids $14: 1 n-5,16: 1 n-7,12: 0,22: 6 n-3$ and 18:0 (in descending order of importance, all with absolute coefficient values greater than 0.25). Axis 2 scores related most strongly to relative amounts of fatty acids $16: 4 n-3,20: 5 n-3$, 16:3n-6, 18:3n-6, 16:2n-6 and 21:5n-3. For harbour porpoise data, the first two PCA axes explained $40.2 \%$ and $9.3 \%$ of variation, respectively, in fatty acid profiles. Axis 1 scores related most strongly to relative amounts of fatty acids 22:6n-3, 21:5n-3, 14:0 and 20:5n-3. Axis 2 scores related most strongly to relative amounts of fatty acids 22:1n-11, 20:1n-11, 18:2n-6, 18:3n-3, 16:0, 18:4n-3 and 18:1n-9.

2.6. Data analysis: description of patterns in the data set

For analysis of geographical variation, samples were grouped into five regions: Scotland, Ireland, Southern North Sea (Netherlands, Belgium and the French coast north of Calais), France (south of Calais, including the entire Biscay coast of France) and Galicia. Average POP concentrations, age and pregnancy rates were summarised by region for both species. Data on HBCD concentrations were available for 60 female common dolphins from Ireland, France and Galicia. For other POPs, sample size increased to 70 (see Table 2). Data on HBCD concentrations were available for 44 female harbour porpoises (mainly from Scotland, Ireland and the southern North Sea) while data on other POPs were available for 67 animals (see Table 3).

To minimise underestimation of pregnancy rate, only mature animals obtained during October to May were included in these estimates, since foetuses present during June to September may be missed during necropsy due to their small size. Since sample sizes are small, where available, literature values for pregnancy rate are also given.

To summarise relationships between POP concentrations in blubber and the set of potential explanatory factors we used redundancy analysis (RDA), as implemented in Brodgar 2.5.1 (www.brodgar.com). Common dolphin and harbour porpoise data were analysed separately. Sample sizes for HBCD concentrations were lower than for other POPs and further analysis of the HBCD data appears in Zegers et al. (2005). Therefore, the RDA excluded the HBCD data. The explanatory factors selected were: geographical location (region), season (quarter of year), size (body length), condition (blubber thickness), age, 
reproductive characters indicative of maturity (combined ovary weights, number of corpora albicantia), pregnancy (presence of foetus in common dolphins or a corpus luteum in porpoises, see above), diet (axis 1 and 2 scores from PCA on fatty acid concentrations in blubber) and trace element concentrations (Cd in kidney, Hg in liver, $\mathrm{Zn}$ in liver and the Hg:Se ratio in liver).

RDA requires that the number of explanatory variables is smaller than the number of samples. We had 67-70 samples and 16-18 explanatory variables, which is an acceptable ratio. RDA assumes that the underlying relationships between variables are generally linear, which was supported by initial data exploration. Significance testing in RDA is based on a permutation test and no assumption of normality is required and collinearity between explanatory variables is not an issue. The analysis makes no assumption that links found represent causal relationships; indeed some of these variables may vary as a consequence of variation in POP burdens rather than being causal factors. Between-species variation in POP concentrations in prey was also analysed using RDA.

\subsection{Modelling individual variation in POP burdens and reproductive status}

To answer specific questions about relationships between variables we used generalised additive models (GAMs). GAM is basically a smoothing equivalent of generalised linear modelling (GLM) (see McCullagh and Nelder 1989; Hastie and Tibshirani, 1990). Although data exploration suggested that the assumption of linearity was generally sound, this approach ensured that no non-linear effects were missed. If smoothing curves for effects of any explanatory variables were found to be approximately linear, a linear (parametric) term was used in place of the smoother and if all smoothing curves were approximately linear we used a GLM. The effects represented by smoothers and parametric terms are marginal effects, i.e. effects of the explanatory variables once effects of all other variables in the model have been taken into account.

In most of the models, the response variable was the (summed) concentration for a class of POPs. The data distributions for log-transformed POP concentrations in cetacean tissues were approximately normal, so a Gaussian distribution with identity link was applied. For models in which pregnancy was the response variable, a binomial distribution and logit link was used. In each case, forwards and backwards selection was applied to find the optimum models. Degrees of freedom for the smoothers were determined using a cross- 
validation procedure. Generally, the best model is that with the lowest value for the Akaike Information Criterion (AIC), in which all remaining explanatory variables have significant effects, and there are no obvious patterns in the residuals.

The specific questions asked were:

(1) Is there geographic variation in blubber POP (summed PCBs, summed PBDEs and HBCD) concentrations once we control for effects of sample composition, i.e. taking into account length, age, reproductive status and season? We used summed ovary weights as a proxy for reproductive status: ovary weights increase as animals mature and are highest in pregnant females. We also test whether adding a condition indicator (dorsal blubber thickness) to the model improved the fit, on the basis that POP concentrations may increase when blubber reserves are mobilised. Missing values resulted in reduced available sample sizes for some of these analyses since GAM requires complete data for all variables (in RDA, missing values are replaced by averages). No blubber thickness data were available for Galician animals so sample size was reduced for all analyses using this variable.

(2) In common dolphins (but not porpoises), RDA analysis indicated a relationship between POP burdens and fatty acid profiles. We therefore fitted GAMs to quantify this relationship. Again we tested the effect of including blubber thickness as an additional explanatory variable to control for the possibility that, when blubber is mobilised, different fatty acids may be utilised at different rates. We also tested whether adding dietary data would improve the models developed to answer question 1.

(3) In harbour porpoises, RDA analysis suggested that POP concentrations were related to trace element concentrations. We therefore fitted GAMs to quantify these relationships.

(4) Are POP concentrations related to health status? Since full pathology data were not available for all animals, we compared POP concentrations (using ANOVA) between broad cause of death categories, in particular distinguishing deaths due to disease or parasites ("pathological” causes) from other known "non-pathological” causes (mainly trauma, including porpoises killed by bottlenose dolphins). Cause of death was unknown in many cases so we also tested whether liver Zn concentration could be used as a proxy for health status by comparing Zn concentrations for different cause of death categories (using Kruskal-Wallis tests). Lastly we used GAMs to quantify the relationships between POP concentrations and Zn concentrations.

(5) Do POP concentrations affect the incidence of pregnancy? 


\section{Results}

\subsection{Patterns of variation in concentrations of POPs}

Explanatory variables related to diet, location, reproductive status and season all affect the overall pattern of variation in POP concentrations in common dolphins (Table 2a). French (but not Irish) animals differed from Galician animals and the significant effects of both fatty acid variables suggest that diet plays an important role in determining the POP profile. Overall, the set of explanatory variables used explained 53\% of the overall variation in POP levels, with RDA axes 1 and 2 accounting for 35\% and $8.3 \%$ of variation respectively. Such relatively "low" values are common in ecological field studies (Zuur et al., 2007). While caution is needed in interpretation, since the first two RDA axes explain only $43 \%$ of variation in POP concentrations, it can be seen from Fig 2 that the variable "pregnancy" is related (negatively) to the concentrations of many of the CB congeners (as indicated by the approximately $180^{\circ}$ angle on the plot between the vectors for the CB congeners and the position of the symbol for pregnancy). Similarly, the effect of combined ovary weight (and/or cadmium levels in the kidney, since they were highly correlated with each other) appears to relate most strongly (and negatively) to concentrations of CB congeners CB28 and CB49. It can also be seen that dietary variation (as proxied by the first PCA axis for the fatty acid profile) relates most strongly to CB28, CB49, HCB and PeCBz. In porpoises, which were sampled mainly from Scotland, Ireland and the southern North Sea, RDA results indicated significant relationships with $\mathrm{Hg}$ and $\mathrm{Zn}$ concentrations in the liver and a weak seasonal effect (Table 2b). Overall, the set of explanatory variables entered into the RDA explained $42 \%$ of variation in POP concentrations between samples, with RDA axes 1 and 2 accounting for $23.8 \%$ and $9 \%$ of variation respectively. The biplot (Fig 3) shows that Zn concentration in liver is strongly positively correlated with the variable "southern North Sea”, as well as with scores on the first PCA axis derived from fatty acid profiles, and negatively correlated with dorsal blubber thickness, Cd concentration in kidney and the variables "Ireland and Galicia". Thus, although the effects of the individual location variables were not statistically significant, it appears that there are important geographical trends in the data. Zinc concentrations in liver are also highly correlated with concentrations of CB49, CB101, CB118, BDE99 and DDE in the blubber.

Variation in POP profiles of prey species was significantly related to geographic location but not to taxonomic groupings (see Table 3). Overall, 57\% of variation in POP 
concentrations was explained by the set of explanatory variables. Particularly high levels of CB49 and CB101 were recorded in southern North Sea prey samples (23 and $168 \mu \mathrm{gg}^{-\mathrm{g}^{-1}}$ respectively in whiting, and 39 and $156 \mu \mathrm{g}^{-g^{-1}}$ in gobies, as compared to averages of 3 and 28 $\mu \mathrm{g} \cdot \mathrm{g}^{-1}$ respectively across all prey taxa from other areas).

\subsection{Regional variation in POP concentrations}

Average summed PCB concentrations in common dolphin blubber were highest in the French sample and lowest in Ireland. The threshold summed PCB concentration at which effects on cetacean reproduction would be expected (which, given the high correlation between summed concentrations of the ICES7 PCBs and all 18 PCBs recorded here, is equivalent to a [ $518 \mathrm{PCB}$ ] of $9.4 \mu \mathrm{g} \mathrm{g}^{-1}$ lipid) was frequently exceeded in both French and Galician common dolphins. Concentrations of PBDEs were rather similar across all countries while HBCD concentrations were higher in Ireland than elsewhere (Table 4a). GAM results for PCBs indicated that both French and Galician dolphins had significantly higher PCB concentrations in their blubber than did Irish animals, there was no region effect on PBDE concentrations and HBCD concentration were significantly lower in Galicia than Ireland (Tables 4a, 5a). Effects of season, age and length were not significant in any of the models. Adding blubber thickness (thereby including a condition effect but excluding Galician data) did not improve the models. However, all three models included a significant and generally negative effect of "maturation" (lower POP concentrations at higher ovary weights, see Figure 4 a,b). The smoother in Figure 4a shows a markedly negative effect of ovary weight on blubber PCB concentration for combined ovary weights over $15 \mathrm{~g}$. Most pregnant dolphins had combined ovary weights over $15 \mathrm{~g}$ while the highest combined ovary weight for a non-pregnant animal was around $14 \mathrm{~g}$.

Although the French sample of common dolphins had the highest pregnancy rate, the sample size for the other areas was small, and a pregnancy rate for Irish animals calculated using a larger data set (see Murphy, 2004) was similar to that obtained for the French animals. In all regions except Galicia, the proportion of animals that had died due to disease, among those for which cause of death was diagnosed, was very low. In Galicia, although there was a high proportion of undiagnosed deaths (over 60\%), where cause of death was diagnosed almost $50 \%$ of the animals had died due to disease or parasite infection (see Table 4a). 
In female harbour porpoises, average summed PCB concentrations were highest in samples from the southern North Sea. PCB concentrations exceeded the threshold for effects on reproduction in almost $3 / 4$ of the southern North Sea sample and over $1 / 3$ of the Scottish sample. PBDE concentrations were higher in porpoises from Scotland than in those from Ireland and Galicia. HBCD concentrations were highest in the samples from Ireland and

518 Scotland, particularly animals from the coast of the Irish Sea (Table 4b). GAM results confirmed that there were significant between-region differences in concentrations of all three categories of POP in porpoise blubber. PCB levels were significantly higher in southern

521 North Sea samples than in Scottish samples. PBDE levels were lower in both Irish and

522 Galician samples than in Scotland, while HBCD concentrations were lower in Galicia than in 523 Scotland (Tables 4b, 5b). Note however that the Galician sample was very small (3 animals). 524 Effects of maturation, length, age and season were all non-significant. When dorsal blubber 525 thickness was added to these models, in all cases its effect was non-significant. Pregnancy rate data for porpoises arising directly from the present study were limited. Only one of seven mature females from the southern North Sea was pregnant (Table 4b). Based on larger sample sets (Learmonth, 2006 and Addink et al., unpublished data), the pregnancy rate for the southern North Sea during 1988-95 (0.59) is higher than that (0.42) recorded for Scotland during 1992-2004. A relatively high proportion of diagnosed deaths was due to disease or parasite infection in all areas except Ireland (0.05), with the highest proportion in the southern North Sea (0.67) (Table 4).

Concentrations of POPs in the two cetacean species can be compared only in Ireland, where sufficient common dolphin and harbour porpoise strandings occurred to provide an adequate sample size. The average PCB and HBCD concentrations in harbour porpoises were higher than those common dolphins.

\subsection{POP concentrations and diet in common dolphins}

GAMs for POP concentrations in common dolphin blubber in relation to fatty acid profiles (PCA scores for axes 1 and 2, i.e. FA1, FA2) explained between 10\% (for PBDEs) and 22\% (for PCBs) of variation (see Table 6). None of these models was significantly improved by including dorsal blubber thickness.

Adding dietary (fatty acid profiles, FA1) data to the GAMs for between-region differences in POPs in common dolphin blubber resulted in improved model fits, with a positive effect of age also remaining in the new final models (Table 6). Regional differences 
547 and effects of combined ovary weight were similar to those found previously. Adding

548 blubber thickness as an additional explanatory variable did not improve these models.

\subsection{POPs, $\mathrm{Hg}$ and Cd concentrations in harbour porpoises}

551

552

553

554

555

556

557

558

559

560

561

562

563

564

565

566

567

568

569

570

571

572

573

574

575

576

577

578

579

Prior to fitting GAMs for effects of metals on POP concentrations in porpoises, the $\mathrm{Cd}$ and $\mathrm{Hg}$ values were square root transformed to reduce the influence of the relatively few very high values. The final model for summed PCB concentrations explained $46 \%$ of deviance $(\mathrm{N}=39)$ and included a negative linear effect of Cd concentration $(\mathrm{P}=0.0008)$ and positive effect of the the Hg:Se ratio ( $\mathrm{Df}=3.8, \mathrm{P}=0.0269$; although non-linear, the smoother was monotonic). No satisfactory model could be fitted to the PBDE or HBCD data. The model for PCBs in porpoises in relation to metal concentrations was not improved by adding age and/or ovary weights as additional explanatory variables.

\subsection{POP concentrations, cause of death and liver Zn concentrations}

In common dolphins, summed PCB and summed PBDE concentrations did not differ significantly between pathological and non-pathological cause of death categories. HBCD concentrations were significantly higher in dolphins that had died of non-pathological causes (ANOVA, $\mathrm{P}=0.0049)$. In contrast, in porpoises, $\mathrm{PCB}(\mathrm{P}=0.0007)$, $\mathrm{PBDE}(\mathrm{P}=0.016)$ and HBCD ( $\mathrm{P}=0.0083)$ concentrations were all significantly higher in animals that had died of pathological causes.

Based on the entire set of samples collected during the project, liver $\mathrm{Zn}$ concentrations and cause of death data were available for 172 common dolphins and 73 porpoises. In common dolphins, only 12 animals had died from pathological causes and there was no significant difference in liver Zn concentrations between these animals and those in the 160 animals that died from other known causes (Kruskal-Wallis test, $\mathrm{H}=1.14, \mathrm{P}=0.285$ ).

In contrast, 34 porpoises had died from pathological causes and on average these had significantly higher liver Zn concentrations than animals that died from other known causes (K-W H=13.12, $\mathrm{P}<0.001)$.

In common dolphins, POP concentrations (PCBs, PBDEs or HBCD) were unrelated to Zn concentration in liver (no satisfactory GAM or GLM could be fitted). In harbour porpoises, PCB concentrations were weakly positively related to liver Zn concentration 
( $\mathrm{P}=0.0428$ ) but there was no significant relationship between PBDE or HBCD concentrations

581 and Zn concentration.

\subsection{Pregnancy and POP burdens}

Data on pregnancy was available for 102 mature female common dolphins over the study period, of which 29 were pregnant. Only four of these 102 animals had died from "pathological" causes, none of which were pregnant, while 80 had died from "nonpathological causes”, of which 25 were pregnant. Thus we cannot test for an association between pregnancy and cause of death category. In harbour porpoises, data on pregnancy were available for 37 mature females, 14 of which were pregnant. Of nine mature females that had died from "non-pathological” causes, five were pregnant while of 19 that had died from "pathological" causes, 5 were pregnant. Although this suggests that there is an association between pregnancy and cause of death category, the association is not significant $\left(\chi^{2}=2.274, \mathrm{DF}=1, \mathrm{P}=0.132\right)$.

In those common dolphins for which POPs data were available, a binomial GLM indicated that the incidence of pregnancy was positively related to age $(\mathrm{P}=0.013, \mathrm{~N}=64$, deviance explained $=13.7 \%)$. This model was improved by adding a linear effect of summed PCB concentrations (deviance explained $=29.7 \%$ ). In this model, age has a positive effect ( $\mathrm{P}=0.0076)$, and summed $\mathrm{PCB}$ concentration has a weak negative effect $(\mathrm{P}=0.0289)$, on the incidence of pregnancy. Using summed PBDE concentrations as an explanatory variable, instead of summed PCBs, age dropped out of the final model. The fitted effect of PBDEs on the incidence of pregnancy was linear and weakly negative $(\mathrm{P}=0.0330)$. This model explained only $11.5 \%$ of deviance but was not improved by adding PCB concentrations as an additional explanatory variable. No satisfactory model of the incidence of pregnancy could be obtained using HBCD concentration as an explanatory variable.

Only six of the sampled porpoises were definitely pregnant and, as might be expected given the imbalance between the numbers of pregnant and non-pregnant models, no satisfactory binomial GAMs using age and POP concentrations could be fitted. The analysis was repeated using incidence of a corpus luteum as the response variable but again no satisfactory model based on age and POP concentrations could be fitted.

\section{Discussion}



sampled animals almost certainly died of other causes, although secondary effects cannot be ruled out. In particular, we were interested in possible effects on reproduction. effects on reproduction in aquatic mammals (Kannan et al., 2000). Since this value was based on comparison with the main peaks in the commercial PCB mixture Aroclor 1254, this level cannot be directly compared with our $\Sigma_{18}$-PCB (or $\Sigma_{16}$-PCB) levels. Following Jepson et al. (2005), we derived the summed concentration of the ICES7 CBs in each sampled animal. Multiplying this figure by three gives a figure that is equivalent to the Aroclor 1254 value reported by Kannan et al. (2000). On this basis, the threshold was frequently exceeded in both porpoises (47\% of individuals) and common dolphins (40\%) in the present study, especially porpoises from the southern North Sea (74\%) and common dolphins inhabiting waters off the French coast (50\%). The threshold was least frequently exceeded in the cetaceans from off Ireland (9\% of common dolphins, 25\% of porpoises). The highest average PCB levels were recorded in porpoises from the southern North Sea. Some caution is however needed in applying this threshold to cetaceans, since the published experimental data all derive from mammals of the order Carnivora (mink, otters and seals). Another issue is the extent to which the sampled animals were representative of the population. Thus, there was a higher proportion of animals that had died due to disease or parasitic infection among the sampled porpoises than among the common dolphins sampled and it is difficult to know whether this reflects the condition of animals in the extant populations.

The present study generated insufficient data to compare pregnancy rates between regions within the study area. However, in common dolphins, the high PCB concentrations recorded in the French sample were associated with a pregnancy rate $(0.30)$ that was slightly higher than the value for Ireland (0.28) reported by Murphy (2004). These figures and the overall pregnancy rate for common dolphins in this study (0.25) are consistent with recently published results for this species in the western North Atlantic, in which annual pregnancy rate was estimated to be between 25 and 33\% (Westgate and Read, 2007).

In common dolphins, the incidence of pregnancy was negatively related to the concentrations of PCBs and PBDEs in blubber. These relationships do not conclusively demonstrate that high POP concentrations inhibit pregnancy since, for example, infertility may allow high levels of POPs to bioaccumulate. Female cetaceans are normally able to 
harbour porpoises, the sample included few pregnant animals and a larger sample size would be needed to detect a link between POP concentrations and pregnancy.

Although it appears that the overall pregnancy rate in porpoises from the southern North Sea in the present study was unusually low (0.14), the sample size for mature females in this area was very low ( $n=7)$. Previous data from porpoises in the Netherlands (1988-1995; M. Addink, T.B. Sørensen, M. García Hartmann and H. Kremer, unpublished data) gave a pregnancy rate of 0.59. Estimated pregnancy rates for Scotland and Ireland from the present study were higher (0.4-0.5) than for the Netherlands but again based on very small sample sizes. Nevertheless, they are consistent with a larger data set for Scotland, based on data from 1991 onwards, for which the pregnancy rate was 0.42 (Learmonth, 2006). The only other published pregnancy rate data available for the southern North Sea is from Danish waters during 1985-1991, where a pregnancy rate of 73\% was estimated using the presence of a foetus (Sorensen and Kinze, 1994). Data from the western Atlantic suggest that the latter rate (or higher) may be more typical of porpoises: in the Bay of Fundy (1985-1988, n=75) and Gulf of Maine (1989-1993, $n=14$ ) the pregnancy rates were 0.74 and 0.93, respectively (Read, 1990; Read and Hohn, 1995). In Iceland, Ólafsdóttir et al. (2003) estimated the pregnancy rate to be $97 \%$ from a sample of by-caught porpoises. It should be noted though that the estimated pregnancy rate for Danish animals could have changed since 1991, and Sorensen and Kinze (1994) analysed samples obtained from all Danish waters, possibly thus including animals from more than one population. Andersen et al. (2001) identified two separate populations (or sub-populations) in Danish waters, based on microsatellite analysis, in the Danish North Sea and in inner Danish waters. Genetic analysis suggests that harbour porpoises from Dutch waters are a mixture of individuals of diverse origin, including a large proportion of migrants from British and Danish waters (Walton, 1997; Anderson et al., 2001). In recent years, there has been a significant increase in the number of harbour porpoises sighted in Dutch waters, which has been attributed to a possible redistribution of harbour porpoises in the North Sea (Camphuysen, 2004; also supported by unpublished results from the SCANS II survey), accompanied by an increase in strandings on the Dutch coast (M.J. Addink, C. Smeenk and E.J.O. Kompanje, unpublished data). Given this evidence of mixing and movements of porpoises, the overall pregnancy rate for porpoises in the North Sea may be more meaningful than figures for smaller areas. lower than in the western Atlantic or Iceland waters and, coupled with evidence of high PCB levels, this is cause for concern. However, estimates of pregnancy rate are subject to 
681 sampling bias (e.g. estimates based on by-caught animals may be higher than those based on strandings) and other biological factors (e.g. nutritional status, population structure) may account for differences in pregnancy rates. Therefore, further investigation of porpoise pregnancy rates in the North Sea and adjacent areas is needed.

Since ingested food represents the only significant post-weaning source of POPs in

686 marine mammal tissues, we would expect to find that POP concentrations vary in relation to diet. However, the initial POP profile of an individual at weaning, accumulated via the placenta and during lactation, presumably reflects the mother's feeding history. POP concentrations in common dolphin blubber were strongly related to the blubber fatty acid profile, which is likely to indicate dependence on diet choice. However, in harbour porpoises there was only weak evidence that diet affects HBCD concentrations and no evidence that it affects PCB and PBDE concentrations.

In the present study we sampled the inner blubber layer to measure fatty acid concentrations since this is the most metabolically active layer and its composition is likely to reflect food intake, as demonstrated for pinnipeds (e.g. Iverson et al., 2004). However, in starving porpoises, thoracic blubber thickness may be reduced by as much as $50 \%$, with lipids being withdrawn mainly from the inner layers (Koopman et al., 2002). It is possible that fatty acids from the inner blubber of porpoises are utilized selectively when blubber reserves are mobilised, so that the dietary signal in the blubber fatty acid profile is confounded.

So called quantitative fatty acid signature analysis (QFASA) has been used to relate fatty acid profiles in predators to diet composition, based on knowledge of the fatty acid profiles of putative prey species (Iverson et al., 2004; Learmonth, 2006). At present it is not possible to use blubber fatty acid profiles to identify the prey species eaten by individual cetaceans. In marine mammals, fatty acids are not deposited in the blubber in proportion to their occurrence in the diet. Although "correction factors" have been derived for some pinnipeds, allowing QFASA to be applied to determine diet (Iverson et al., 2004), no such correction factors are presently available for cetaceans. Our results for porpoises suggest, furthermore, that blubber fatty acid profiles may not be a good indicator of diet when animals are in poor condition. At least it will be necessary to control for variation in condition.

The RDA results suggested that patterns of variation in certain POPs were more strongly related to diet than others. Thus variation in concentrations of CB28, CB49 and HCB was most closely related to dietary variation in common dolphins. The limited survey of prey species carried out in the present study suggested that regional variation in POP 
profiles outweighed taxonomic variation. However, further more extensive surveys of POP concentrations in putative prey species are needed to quantify variation in POP profiles.

In harbour porpoises, body size and geographical location were the main factors explaining variation in POP concentrations. This general pattern was supported by both RDA (which detects linear effects of explanatory variables on the suite of response variables) and GAM (which allows only one response variable but permits detection of non-linear effects of explanatory variables). Our survey of POP concentrations in prey tissues showed that prey samples from the southern North Sea had high POP concentrations, particularly for CB congeners CB49 and CB101.

This study focussed on concentrations of various POPs in the blubber of two species of small cetaceans. Although there have been many previous surveys, the present study was the first to both cover a large proportion of the European Atlantic coast and to evaluate the explanatory variables underlying the observed pattern of variation. In general it is not possible to collect the necessary ancillary data from studies on living animals (except where the history of individual animals in a population is known, c.f. Wells et al., 2005) and the cost of a large-scale, biopsy-based, survey of POP concentrations in European small cetaceans would have been prohibitive. By surveying stranded (and by-caught) animals, all the required data can be collected in a cost-effective and non-invasive manner, while minimising errors due to decomposition prior to sampling by selecting only the freshest carcasses. Sampling biases can to some extent be controlled for in subsequent analysis. One difficulty when faced with a large set of putative explanatory variables, not all of which are independent, is teasing out effects of each, especially as different variables provide different levels/kinds of explanation. For example, one set of analyses described above suggests that POP concentrations in blubber are strongly related to mercury concentrations in liver and cadmium concentrations in kidney. It is unlikely that this represents cause and effect since, for example, metal concentrations are also related to age and maturity (Lahaye et al., 2005, In Press). Cadmium levels were higher in common dolphins than in porpoises, perhaps related to feeding in offshore waters and/or the presence of oceanic squids (which are known to accumulate large amounts of cadmium) in their diet (Bustamante et al., 1998; Lahaye et al., 2005).

In porpoises, the highest blubber PCB concentrations were recorded from animals sampled on southern North Sea coasts. Results from the present study, as well as published sources and other recent unpublished data (M. Garcia-Hartmann, T. Jauniaux, unpubl data) indicate that a high proportion of porpoises stranded on the coasts of the Netherlands and 
Belgium suffered from potentially fatal diseases. Pneumonia accounted for a greater percentage (49\%) of deaths of stranded harbour porpoise on the Belgian and northern French coasts (1990-2000) (Jauniaux et al., 2002), compared to the Scottish coast (1992-2004), where pneumonia accounted for 11\% of known deaths (Learmonth, 2006) and in England and Wales (1991-2002), where 15\% of harbour porpoise deaths for which cause was established were attributed to pneumonia (Jepson, 2003). In addition, severe emaciation was the most common condition found in 33 of 55 harbour porpoises examined from Belgian and northern French coasts (Jauniaux et al., 2002).

In general, high concentrations of PCBs are thought to increase susceptibility to disease (e.g. in porpoises, Jepson et al., 2005) and may also be associated with higher parasite burdens (Bull et al., 2006). Only a small proportion of sampled common dolphins had died from pathological causes and no association was found between PCB concentrations and cause of death. Ideally the analysis should be repeated once a larger sample of animals that died from pathological causes is available. In contrast, almost half the porpoises for which cause of death was determined had died from pathological causes and these animals had significantly higher concentrations of all classes of POPs than animals dying from other causes. They also had higher Zn concentrations in their liver, which may be indicative of poor health (Das et al., 2004). Indeed, it is well-established that infection is associated with Zn redistribution in humans, and, in particular, that high concentrations in liver rise as a result of acute-phase protein synthesis (Scott, 1985; Hambridge et al., 1986; Amdur et al., 1991). While there was apparently a strong relationship between the overall POP profile and Zn concentration in porpoises, relationships with summed concentrations for individual POP classes were weak. Further study is thus needed to determine which POPs might be linked to effects on health.

\section{Acknowledgements}

This work formed part of the EU-funded BIOCET project (Bioaccumulation of persistent organic pollutants in small cetaceans in European waters: transport pathways and impact on reproduction, EVK3-2000-00027). We are grateful to our Project Officer, Cathy Eccles for her support. The UK marine mammal strandings program, funded by DEFRA as part of its commitment to the Agreement on the conservation of Small Cetaceans of the Baltic and North Seas, supported attendance at strandings, necropsies and some POPs analyses for UK animals. We thank Tony Patterson and Paul Jepson for their contributions to data collection 
in the UK. In Ireland, members of the Irish Whale and Dolphin Group assisted with data collection. Jérôme Spitz and other members of CRMM assisted with collection of samples from the French Atlantic coast. Members of CEMMA attended strandings in Galicia. Claude Joiris, Jean-Marie Bouquegnau and Ludo Holsbeek kindly provided access to Belgian samples. We are also grateful for the collaboration of the Dutch strandings network. Jamie Banks, Sarah Bannon, Fiona Read, Gabi Stowasser assisted with fatty acid analysis. Lindsay Brown assisted with collating literature and Jianjun Wang drew the maps in Fig 1. We thank colleagues in the BIOCET project and two anonymous referees for useful comments on the manuscript.

\section{References}

Addison, R.F., 1989. Organochlorines and marine mammal reproduction. Canadian Journal of Fisheries and Aquatic Sciences 46, 360-368.

Aguilar, A., Borrell, A., Pastor, T. 1999. Biological factors affecting variability of persistent pollutant levels in cetaceans. Journal of Cetacean Research and Management Special Issue 1, 83-116.

Allchin, C.R., Morris, S. 2003. Hexabromocyclododecane (HBCD) diastereomers and brominated diphenyl ether congener (BDE) residues in edible fish from the rivers Skerne and Tees, U.K. Organohalogen Compounds 61, 41-44.

Amdur, M.O., Doull, J., Klaassen, C.D., 1991. Toxicology: the Basic Science of Poisons. New York: McGrawHill.

Andersen, L.W., Ruzzante, D.E. Walton, M., Berggren, P., Bjorge, A., Lockyer, C. 2001. Conservation genetics of harbour porpoises, Phocoena phocoena, in eastern and central North Atlantic. Conservation Genetics 2, 309-324.

Bligh, E.G., Dyer, W.J., 1959. A rapid method of total lipid extraction and purification. Canadian Journal of Biochemistry and Physiology 37, 911-917.

Boon, J.P., van der Meer, J., Allchin, C.R., Law, R.J., Klunsoyr, J., Leonards, P.E.G., Spliid, H., Storr-Hansen, E., McKenzie, C., Wells, D.E., 1997. Concentration-dependent changes of PCB patterns in fish-eating mammals: structural evidence for induction of cytochrome P450. Archives of Environmental Contamination and Toxicology 33, 298-311.

Boon, J.P., Lewis, W.E., Tjoen-A-Choy, M.R., ten Hallers-Tjabbes, C.C., Allchin, C.R., Law, R.J., de Boer, J., Zegers, B.N., 2002. Levels of polybrominated diphenyl ether (PBDE) flame retardants in animals representing different trophic levels of the North Sea food web. Environmental Science and Technology 36, 4025-4032.

Bull, J.C., Jepson, P.D., Ssuna, R.K., Deaville, R., Allchin, C.R., Law, R.J., Fenton, A., 2006. The relationship between polychlorinated biphenyls in blubber and levels of nematode infestations in harbour porpoises, Phocoena phocoena. Parasitology 132, 565-573. 

cadmium to top marine predators in the north-east Atlantic Ocean. Science of the Total Environment 220, 7180.

824 Camphuysen, K., 2004. The return of the harbour porpoise (Phocoena phocoena) in Dutch coastal waters. Lutra 47, 135-144.

Darnerud, P.O. (2003). Toxic effects of brominated flame retardants in man and in wildlife. Environment International 29, 841-853.

Das, K., Siebert, U., Fontaine, M., Jauniaux, T., Holsbeek, L., Bouquegneau J.M., 2004. Ecological and pathological factors related to trace metal concentrations in harbour porpoises Phocoena phocoena from the North Sea and adjacent areas. Marine Ecology Progress Series 281, 283-295.

De Boer, J., Wester, P.G., Klamer, H.J.C., Lewis, W.E., Boon, J.P., 1998. Do flame retardants threaten ocean life? Nature 394, 28-29.

De Guise, S., Martineau, D., Beland, P., Fournier, M., 1995. Possible mechanisms of action of environmental contaminants on St Lawrence beluga whales (Delphinapterus leucas). Environmental Health Perspectives 103(S4), 73-77.

De Pierrepont, J.F., Dubois, B., Desormonts, S., Santos, M.B., Robin J. P., 2005. Stomach contents of English Channel cetaceans stranded on the coast of Normandy, Journal of the Marine Biological Association of the United Kingdom 85, 1539-1546.

De Swart, R.L. 1995. Impaired immunity in seals exposed to bioaccumulated environmental contaminants. PhD thesis. Erasmus Universiteit, Rotterdam.

Elsner, R., 1999. Living in water: solutions to physiological problems. In: Reynolds, J.E. III, Rommel, S.A. (Eds). Biology of Marine Mammals. Smithsonian Institution Press, Washington and London.

Godard, C.A., Leaver, M.J., Said, M.R., Dickerson, R.L., George, S., Stegeman, J.J., 2000. Identification of cytochrome P450 1B-like sequences in two teleost fish species (scup, Stenotomus chrysops and plaice, Pleuronectes platessa) and in a cetacean (striped dolphin, Stenella coeruleoalba). Marine Environmental Research 50, 7-10.

Goksøyr A. 1995. Cytochrome P450 in marine mammals: isozyme forms, catalytic functions and physiological regulations. In: Blix, S., Walløe, L., Ulltang, O. (Eds). Whales, Seals, Fish and Man. Elsevier Science, Amsterdam, pp. 629-639.

Hall, A.J., Hugunin, K., Deaville, R., Law, R.J., Allchin, C.R., Jepson, P.D., 2006. The risk of infection from polychlorinated biphenyl exposure in harbor porpoise (Phocoena phocoena): a case-control approach.

853 Hambridge, K.M., Casey, C.E., Krebs, N.F., 1986. Zinc. In: Mertz, W. (Ed.), Trace Metals in Human and Animal Nutrition, vol. 2. Academic Press, Orlando, pp. 53-57.

855 Hanson, S.W.F., Olley, J., 1963. Application of the Bligh and Dyer method of lipid extraction to tissue 856 homogenates. Biochemistry Journal 89, 101-102.

857 Hastie, T.J., Tibshirani, R.J., 1990. Generalized additive models. Chapman and Hall, London.

858 Helle, E., Olsson, M., Jensen, S., 1976. PCB levels correlated with pathological changes in seal uteri. Ambio 5, 859 261-263. 
Hohn, A.A., Lockyer, C., 1995. Protocol for obtaining age estimates from harbour porpoise teeth. Appendix 3, Report of the harbour porpoise age determination workshop, Oslo, 21-23 May 1990. Report of the International Whaling Commission 16 (Biology of Phocoenids), pp. 478-493.

Hummert, K., Vetter, W., Luckas, B., 1995. Levels of alpha-HCH, Lindane, and enantiomeric ratios of alpha$\mathrm{HCH}$ in marine mammals from the northern hemisphere. Chemosphere 31, 3489-3500.

Iverson, S.J., Field, C., Bowen, W.D., Blanchard, W., 2004. Quantitative fatty acid signature analysis: a new method of estimating predator diets. Ecological Monographs 74, 211-235.

Jauniaux, T., Petitjean, D., Brenez, C., Borrens, M., Brosens, L., Haelters, J., Tavernier, T., Coignoul, F., 2002. Post-mortem findings and causes of death of harbour porpoises (Phocoena phocoena) stranded from 1990 to 2002 along the coastlines of Belgium and Northern France. Journal of Comparative Pathology 126, 243-253.

Jepson, P.D., 2003. Pathology and toxicology of stranded harbour porpoises (Phocoena phocoena) in UK waters. PhD Thesis, Royal Veterinary College, University of London.

Jepson, P.D., Bennett, P.M., Deaville, R., Allchin, C.R., Baker, J.R., Law, R.J., 2005. Relationships between polychlorinated biphenyls and health status in harbor porpoises (Phocoena phocoena) stranded in the United Kingdom. Environmental Toxicology and Chemistry 24, 238-248.

Kannan, K., Blankenship, A.L., Jones, P.D., Giesy, J.P., 2000. Toxicity reference values for the toxic effects of polychlorinated biphenyls to aquatic mammals. Human and Ecological Risk Assessment 6, 181-201.

Koopman, H.N., Iverson, S.J., Gaskin, D.E., 1996. Stratification and age-related differences in blubber fatty acids of the male harbour porpoise (Phocoena phocoena). Journal of Comparative Physiology B Biochemical Systemic and Environmental Physiology 165, 628-639.

Koopman, H.N., Pabst, D.A., McLellan, W.A., Dillaman, R.M., Read, A.J., 2002. Changes in blubber

Kuiken, T., Hartmann, M.G. (Eds), 1991. Cetacean pathology: dissection techniques and tissue sampling. Special Publication. European Cetacean Society, no. 17.

Lahaye, V., Bustamante, P., Spitz, J., Dabin, W., Das, K., Pierce, G.J., Caurant, F., 2005. Long-term dietary segregation of common dolphins (Delphinus delphis) in the Bay of Biscay, determined using cadmium as an ecological tracer. Marine Ecology Progress Series 305, 275-285.

Lahaye, V., Bustamante, P., Law, R.J., Learmonth, J.A., Santos, M.B., Boon, J.P., Rogan, E., Dabin, W., Addink, M.J., López, A., Zuur, A.F., Pierce, G.J., Caurant, F., In Press. Biological and ecological factors related to trace element levels in harbour porpoises (Phocoena phocoena) from European waters. Marine Environmental Research.

Law, R.J., Bersuder, P., Allchin, C.R., Barry, J., 2006b. Levels of the flame retardants hexabromocyclododecane and tetrabromobisphenol A in the blubber of harbour porpoises (Phocoena phocoena) stranded or bycaught in the U.K., with evidence for an increase in HBCD concentrations in recent years. Environmental Science and Technology 40, 2177-2183.

Law, R.J., Kohler, M., Heeb, N.V., Gerecke, A.C., Schmid, P., Voorspoels, S., Covaci, A., Becher, G., Janák, K., Thomsen, C., 2005. Hexabromocyclododecane challenges scientists and regulators. Environmental Science and Technology 39, 281A-287A. 
Law, R.J., Kohler, M., Heeb, N.V., Gerecke, A.C., Schmid, P., Voorspoels, S., Covaci, A., Becher, G., Janák, K. and Thomsen, C., 2006a. Response to "HBCD: facts and insinuations". Environmental Science and Technology 40, 2.

Learmonth, J.A., 2006. Life history and fatty acid analysis of harbour porpoises (Phocoena phocoena) from Scottish waters. PhD Thesis, University of Aberdeen.

Lockyer, C., 1995. Investigation of aspects of the life history of the harbour porpoise, Phocoena phocoena, in British waters. Report of the International Whaling Commission Special Issue 18, 189 - 199.

Lockyer, C., Desportes, G., Hansen, K., Labberté, S., Siebert, S., 2003. Monitoring growth and energy utilisation of the harbour porpoise (Phocoena phocoena) in human care. In: Harbour Porpoises in the North Atlantic (eds Haug, T., Desportes, G., Víkingsson, G.A., Witting, L.), NAMMCO Scientific Publications, Volume 5: 107-120.

Martoja, R., Berry, J.P., 1980. Identification of tiemannite as a probable product of demethylation of mercury by selenium in cetaceans: a complement to the scheme of the biological cycle of mercury. Vie Mileau 30, 7-10.

McCullagh, P, Nelder, J.A., 1989. Generalized Linear Models. Second Edition. Chapman and Hall, London.

Murphy, S., 2004. The biology and ecology of the short-beaked common dolphin Delphinus delphis in the North-east Atlantic. PhD thesis, University College, Cork.

916 Ólafsdóttir, D., Víkingsson, G. A., Halldórsson, S. D., Sigurjónsson, J. 2003. Growth and reproduction in harbour porpoises (Phocoena phocoena) in Icelandic waters. NAMMCO Scientific Publications 5, 195-210.

Pusineri, C., Magnin, V., Meynier, L., Spitz, J., Hassani, S., Ridoux, V., 2007. Food and feeding ecology of the common dolphin (Delphinus delphis) in the oceanic Northeast Atlantic and comparison with its diet in neritic areas, Marine Mammal Science 23, 30-47.

Read, A.J., 1990. Age at sexual maturity and pregnancy rates of harbour porpoises Phocoena phocoena from the Bay of Funday. Canadian Journal of Fisheries and Aquatic Science 47, 561-565.

Read, A.J., Hohn, A.A., 1995. Life in the fast lane: the life history of harbour porpoises from the Gulf of Maine. Marine Mammal Science 11, 423-440.

Reijnders, P.J.H., 1984. Man-induced factors in relation to fertility changes in pinnipeds. Environmental Conservation 11, 61-65.

Reijnders, P.J.H., 1986. Reproductive failure in common seals feeding on fish from polluted coastal waters. Nature 324, 456-457.

Ross, P.S., 1995. Seals, pollution and disease: environmental contaminant-induced immuno-suppression. PhD thesis, Universiteit Utrecht, Utrecht.

Santos, M.B., Pierce, G.J., 2003. The diet of harbour porpoise (Phocoena phocoena) in the Northeast Atlantic. Oceanography \& Marine Biology: An Annual Review 41, 355-390.

Santos, M.B., Pierce, G.J., Ieno, E.N., Addink, M., Smeenk, C., Kinze, C.C., 2005. Harbour porpoise (Phocoena phocoena) feeding ecology in the eastern North Sea. International Council for the Exploration of the Sea CM 2005/R:15.

Santos, M.B., Pierce, G.J., Learmonth, J.A., Reid, R.J., Ross, H.M., Patterson, I.A.P., Reid, D.G., Beare, D., 2004. Variability in the diet of harbor porpoises (Phocoena phocoena) in Scottish waters 1992-2003. Marine Mammal Science 20, 1-27. 
Santos, M.B., Pierce, G.J., López, A., Martínez, J.A., Fernández, M.T., Ieno, E., Mente, E., Porteiro, C., Carrera, P., Meixide, M., 2004. Variability in the diet of common dolphins (Delphinus delphis) in Galician waters 1991-2003 and relationship with prey abundance. International Council for the Exploration of the Sea CM 2004/Q:09.

Schwacke, L.H., Voit, E.O., Hansen, L.J., Wells, R.S., Mitchum, G.B., Hohn, A.A., Fair, P.A., 2002. Probabilistic risk assessment of reproductive effects of polychlorinated biphenyls on bottlenose dolphins (Tursiops truncatus) from the Southeast United States coast. Environmental Toxicology and Chemistry 21, 2752-2764.

Scott, M.L., 1985. Nutrition of Humans and Selected Animal Species. John Wiley, New York.

Sellström, U., Bignert, A., Kierkegaard, A., Häggberg, L., de Wit, C.A., Olsson, M., Jansson, B., 2003. Temporal trend studies on tetra-and pentabrominated diphenyl ethers and hexabromocyclododecane in guillemot egg from the Baltic Sea. Environmental Science and Technology 37, 5496-5501.

Sørensen, T.B., Kinze, C.C., 1994. Reproduction and reproductive seasonality in Danish harbour porpoises, Phocoena phocoena. Ophelia 39,159-176.

Walton, M. J. 1997. Population structure of harbour porpoises Phocoena phocoena in the seas around the UK and adjacent waters. Proceedings of the Royal Society of London. Series B. Biological Sciences 264, 89-94.

Wells, R.S. Tornero, V., Borrell, A., Aguilar, A., Rowles, T.K., Rhinehart, H.L., Hofmann, S., Jarmane, W.M., Hohn, A.A., Sweeney, J.C., 2005. Integrating life-history and reproductive success data to examine potential relationships with organochlorine compounds for bottlenose dolphins (Tursiops truncatus) in Sarasota Bay, Florida. Science of the Total Environment 349, 106- 119.

Westgate, A.J., Read, A.R., 2007. Reproduction in short-beaked common dolphins (Delphinus delphis) from the western North Atlantic. Marine Biology 150, 1011-1024.

White, R.D., Hahn, M.E., Lockhart, W.L., Stegeman, J.J., 1994. Catalytic and immunochemical characterization of hepatic microsomal cytochromes P450 in Beluga whale (Delphinapterus leucas). Toxicology and Applied Pharmacology 126, 45-57.

Zegers, B.N., Lewis, W.E., Booij, K., Smittenberg, R.H., Boer, W., de Boer, J., Boon, J.P., 2003. Levels of polybrominated diphenyl ether flame retardants in sediment cores from Western Europe. Environmental Science and Technology 37, 3803-3807.

Zegers, B.N., Mets, A., Van Bommel, R., Minkenberg, C., Hamers, T., Kamstra, J.H., Pierce, G.J., Boon, J.P., 2005. Levels of Hexabromocyclododecane in harbor porpoises and common dolphins from Western European seas, with evidence for stereoisomer-specific biotransformation by cytochrome P450. Environmental Science and Technology 39, 2095-2100.

Zuur, A.F., Ieno, E.N., Smith, G.M., 2007. Analysing Ecological Data. Springer-Verlag. 
Table 1.

Prey samples analysed for persistent organic pollutants (POP) concentrations: (a) fish and (b) cephalopods. Region codes: 1 = UK (Scotland), 2 = Ireland, $3=$ Netherlands/Belgium, 4 = France, 5 = Spain (Galicia). Note: for Spanish fish samples, separate POP analyses were carried out on liver and muscle. Otherwise, whole animals were used.

(a) Fish

\begin{tabular}{ll}
\hline TAXON & SOURCES \\
\hline Ammodytidae & 1,5 \\
Clupea harengus & 1 \\
Gadiculus argenteus & 4 \\
Lampanyctos festivus & 4 \\
Limanda limanda & 1 \\
Melanogrammus aeglefinus & 1 \\
Merlangius merlangus & $1,2,3$ \\
Merluccius merluccius & 5 \\
Micromesistius poutassou & 5 \\
Notoscopelus kroyeri & 4 \\
Pleuronectes platessa & 1 \\
Pollachius virens & 1 \\
Pomatoschistus spp & 3 \\
Sardina pilchardus & 4,5 \\
Scomber scombrus & 1 \\
Sprattus sprattus & 1 \\
Trachurus trachurus & 4 \\
Triglidae & 1 \\
Trisopterus esmarkii & 1 \\
Trisopterus luscus & 4,5 \\
\hline
\end{tabular}

(b) Cephalopods

\begin{tabular}{ll}
\hline TAXON & SOURCES \\
\hline Illex coindetii & 5 \\
Loligo vulgaris & 4,5 \\
Octopus vulgaris & 5 \\
Todaropsis eblanae & 5 \\
\hline
\end{tabular}


Table 2.

Results of redundancy analysis (RDA) on concentrations of POPs (excluding HBCDs) in blubber of female small cetaceans. Values of $F$ and associated probability $(\mathrm{P})$ are tabulated. For nominal variables (season or quarter, region, pregnancy), one value is always excluded and used as a basis for comparison.

(a) Common dolphins

\begin{tabular}{lcc}
\hline Explanatory variable & F & P \\
\hline France & 10.01 & $\mathbf{0 . 0 0 0}$ \\
Fatty acid profile (PCA axis 1) & 8.41 & $\mathbf{0 . 0 0 1}$ \\
Number of corpora albicantia & 5.21 & $\mathbf{0 . 0 0 7}$ \\
Quarter 2 & 5.18 & $\mathbf{0 . 0 0 7}$ \\
Fatty acid profile (PCA axis 2) & 4.65 & $\mathbf{0 . 0 0 9}$ \\
Length & 3.67 & $\mathbf{0 . 0 2 2}$ \\
Pregnancy & 3.40 & $\mathbf{0 . 0 2 9}$ \\
Ireland & 2.23 & 0.090 \\
Age & 1.97 & 0.119 \\
Hg:Se ratio in liver & 1.95 & 0.122 \\
Zinc concentration in liver & 1.54 & 0.188 \\
Cadmium concentration in kidney & 1.08 & 0.305 \\
Quarter 1 & 0.89 & 0.387 \\
Mercury concentration in liver & 0.33 & 0.825 \\
Combined ovary weights & 0.30 & 0.850 \\
Quarter 3 & 0.12 & 0.971 \\
\hline
\end{tabular}

(b) Harbour porpoises

\begin{tabular}{lcc}
\hline Explanatory variable & F & P \\
\hline Zinc concentration in liver & 4.79 & $\mathbf{0 . 0 0 9}$ \\
Mercury concentration in liver & 5.00 & $\mathbf{0 . 0 1 1}$ \\
Quarter 3 & 2.92 & $\mathbf{0 . 0 3 4}$ \\
Cadmium concentration in kidney & 2.73 & 0.065 \\
Netherlands/Belgium & 2.38 & 0.065 \\
Length & 2.36 & 0.070 \\
Ireland & 2.38 & 0.072 \\
Galicia & 2.30 & 0.080 \\
Mercury:selenium ratio in liver & 2.21 & 0.091 \\
Dorsal blubber thickness & 1.32 & 0.233 \\
Number of corpora albicantia & 1.32 & 0.238 \\
France & 0.80 & 0.409 \\
Fatty acid profile (PCA axis 2) & 0.79 & 0.469 \\
Quarter 1 & 0.78 & 0.476 \\
Quarter 2 & 0.53 & 0.686 \\
Fatty acid profile (PCA axis 1) & 0.35 & 0.860 \\
Combined ovary weights & 0.19 & 0.970 \\
Age & 0.14 & 0.989 \\
Presence of a corpus luteum & 0.05 & 1.000 \\
\hline
\end{tabular}


Table 3.

Results of RDA on POPs in prey species. The analysis was based on species averages (so size variation within species is not taken into account), $n=30$. Values of $F$ and associated probability $(\mathrm{P})$ are tabulated.

\begin{tabular}{lcc}
\hline Explanatory variable & F & P \\
\hline Netherlands & 11.15 & $\mathbf{0 . 0 0 0}$ \\
France & 4.19 & $\mathbf{0 . 0 0 4}$ \\
Fatty acid profile (PCA axis 1) & 1.95 & 0.099 \\
Spain & 1.11 & 0.342 \\
Clupeioid & 1.12 & 0.310 \\
Gadoid & 1.136 & 0.325 \\
Mackerel/scad & 0.87 & 0.383 \\
Cephalopod & 0.86 & 0.466 \\
Sandeel & 0.84 & 0.434 \\
Fatty acid profile (PCA axis 2) & 0.43 & 0.771 \\
Scotland & 0.21 & 0.907 \\
Myctophid & 0.18 & 0.961 \\
\hline
\end{tabular}


Table 4.

Regional summaries of blubber POP concentrations female small cetaceans. Values tabulated are arithmetic means, with standard deviations (where available) and sample sizes in parentheses. Also given are "region" coefficients for the GAM models (see Table 5), indicating differences in POP concentrations relative to samples from the reference region, taking account of the effects of reproductive status. Positive coefficient values indicate significantly higher levels, negative values indicate significantly lower levels and "nsd" indicates no significant difference. "Southern North Sea" data for porpoises include data from the Netherlands, Belgium and northern France, the latter data therefore being excluded from the "France" category. Pregnancy rate and the proportion of (known cause) deaths recorded that were due to disease or parasites.

(a) Common dolphins

\begin{tabular}{lccccc}
\hline Parameter & Scotland & Ireland & France & Galicia & All regions \\
\hline$\Sigma 18[$ PCBs], ng/g lipid & - & $3649(3394,11)$ & $13692(12721,36)$ & $10955(11563,23)$ & $11215(11779,70)$ \\
GAM coefficient for PCBs & - & reference & 0.651 & 0.644 & - \\
$3 \times \Sigma[$ ICES7 PCBs] & - & $6919(6404,11)$ & $24644(22938,36)$ & $19875(20797,23)$ & $20292(21194,70)$ \\
Proportion above critical & - & $0.09(11)$ & $0.50(36)$ & $0.39(23)$ & $0.40(70)$ \\
\hline$\Sigma 5[$ PBDEs], ng/g lipid & - & $758(505,11)$ & $612(413,36)$ & $422(182,23)$ & $573(384,70)$ \\
GAM coefficient for PBDEs & - & reference & nsd & nsd & - \\
[HBCD], ng/g lipid & - & $1086(1137,7)$ & $433(211,31)$ & $185(101,23)$ & $415(478,61)$ \\
GAM coefficient for HBCD & & reference & nsd & -0.485 & - \\
\hline Age, years & $8.40(8.38,5)$ & $9.03(8.45,27)$ & $11.31(6.24,95)$ & $6.43(5.27,51)$ & $9.48(6.72,178)$ \\
Disease/parasite deaths & $0.08(13)$ & $0(42)$ & $0(252)$ & $0.49(51)$ & $0.07(358)$ \\
Pregnancy rate & - & $0.14(7)$ & $0.30(66)$ & $0.06(16)$ & $0.25(91)$ \\
Pregnancy rate (literature) & & $0.282^{*}$ & & & \\
\hline
\end{tabular}

* Based on 37 sexually mature females, 1991-2004, see Murphy (2004). 
Table 4 (continued)

(b). Harbour porpoises

\begin{tabular}{|c|c|c|c|c|c|c|}
\hline Parameter & Scotland & Ireland & Southern N Sea & France & Galicia & All Areas \\
\hline$\Sigma 16[$ PCBs], ng/g lipid & $10525(13152,31)$ & $5347(4750,12)$ & $15021(8574,19)$ & $13809(10582,2)$ & $5306(4199,3)$ & $10737(10811,67)$ \\
\hline GAM coefficient for PCBs & reference & nsd & 0.287 & nsd & nsd & - \\
\hline $3 \times \Sigma[$ ICES7 PCBs $]$ & $20320(25243,31)$ & $10492(9451,12)$ & $30598(17994,19)$ & $27600(20872,2)$ & $10266(7972,3)$ & $21242(21277,67)$ \\
\hline Proportion above critical & $0.39(31)$ & $0.25(12)$ & $0.74(19)$ & $0.50(2)$ & $0.33(3)$ & $0.46(67)$ \\
\hline$\Sigma 5[$ PBDEs], ng/g lipid & $1369(1352,31)$ & $656(492,12)$ & $1056(803,19)$ & $1398(939,2)$ & $284(44,3)$ & $1105(1079,67)$ \\
\hline GAM coefficient for PBDEs & reference & -0.289 & nsd & nsd & -0.549 & - \\
\hline [HBCD], ng/g lipid & $2236(2562,20)$ & $2961(2716,7)$ & $1080(354,12)$ & $1533(1101,2)$ & $121(37,3)$ & $1860(2154,44)$ \\
\hline GAM coefficient for HBCD & reference & nsd & nsd & - & -1.127 & \\
\hline Age, years & $2.92(2.79,56)$ & $3.36(3.32,21)$ & $4.97(3.92,15)$ & $6.61(8.10,7)$ & $0.92(0.20,6)$ & $3.44(3.69,105)$ \\
\hline Disease/parasite deaths & $0.54(105)$ & $0.05(22)$ & $0.67(21)$ & $0.32(19)$ & $0.25(4)$ & $0.46(171)$ \\
\hline Pregnancy rate & $0.5(10)$ & $0.4(5)$ & $0.14(7)$ & - & - & $0.42(26)$ \\
\hline Pregnancy rate (literature) & $0.42^{*}$ & & $0.59 * *$ & & & \\
\hline
\end{tabular}

* Based on 33 mature females, 1992-2004 (Learmonth, 2006)

** Based on 27 mature females, 1988-1995 (M. Addink, T.B. Sørensen, M. García Hartmann and H. Kremer, unpublished data) 
Table 5.

GAM results for regional patterns in POP concentrations in blubber of female small cetaceans. The original set of explanatory variables was: region, maturation/reproductive status (proxied by combined ovary weight, COW), age, length and season. Model summaries contain the following information: sample size $(\mathrm{N})$, \%deviation explained (\%dev), Akaike Information Criterion (AIC) value, and effects of region and COW, with associated probabilities (P). Degrees of freedom (Df) are indicated for smoothers and the direction of the effect is indicated for categorical and linear terms. For region effects, the direction of the effect is expressed relative to a reference region. Only the significant regional differences are reported.

(a) Common dolphin (reference region: Ireland)

\begin{tabular}{llllll}
\hline Response & $\mathrm{N}$ & \%dev & AIC & Region & COW \\
\hline$\Sigma 18[$ PCB] & 58 & 42.9 & 64.4 & $\begin{array}{l}\text { France: }+, \mathrm{P}<0.0001 \\
\text { Galicia: }+, \mathrm{P}=0.0002\end{array}$ & $\mathrm{Df}=4.2, \mathrm{P}=0.0169$ \\
& & & & &,$- \mathrm{P}=0.0096$ \\
$\Sigma 5[\mathrm{PBDE}]$ & 58 & 11.4 & 32.2 & & \\
HBCDs & 50 & 50.5 & -3.0 & Galicia:,$- \mathrm{P}<0.0001$ & $\mathrm{Df}=1.6, \mathrm{P}=0.0372$ \\
\hline
\end{tabular}

(b) Harbour porpoise (reference region: Scotland)

\begin{tabular}{llllll}
\hline Response & $\mathrm{N}$ & \%dev & AIC & Region & COW \\
\hline$\Sigma 16[$ PCB $]$ & 66 & 17.8 & 74.0 & SN Sea:,$+ \mathrm{P}=0.0164$ & \\
$\Sigma 5[\mathrm{PBDE}]$ & 66 & 19.6 & 40.4 & Ireland: -, $\mathrm{P}=0.0081$ & \\
& & & & Galicia: -, $\mathrm{P}=0.0049$ & \\
HBCDs & 43 & 44.5 & 37.2 & Galicia: -, $\mathrm{P}<0.0001$ & \\
\hline
\end{tabular}


Table 6.

GAM results for dietary patterns in POP concentrations in blubber of female common dolphins. The explanatory variables were the $1^{\text {st }}$ and 2 nd axis scores from a PCA on fatty acid data (FA1, FA2). In addition, the table presents the final models from Table 5 revised to include dietary information. Model summaries contain the following information: sample size (N), \%deviation explained (\%dev), Akaike Information Criterion (AIC) value, and effects of explanatory variables, with associated probabilities (P). Degrees of freedom (Df) are indicated for smoothers and the direction of the effect is indicated for categorical and linear terms. For region effects, the direction of the effect is expressed relative to a reference region. Only the significant regional differences are reported.

(a) Models using fatty acid data only

\begin{tabular}{llllll}
\hline Compounds & $\mathrm{N}$ & \%dev & AIC & FA1 & FA2 \\
\hline$\Sigma 18[\mathrm{PCB}]$ & 67 & 21.7 & 86.3 & $\mathrm{Df}=3.8, \mathrm{P}=0.0137$ & \\
$5[\mathrm{PBDE}]$ & 67 & 9.9 & 40.0 &,$+ \mathrm{P}=0.0096$ & \\
HBCDs & 58 & 14.8 & 38.6 & &,$+ \mathrm{P}=0.0029$ \\
\hline
\end{tabular}

(b) Models also including effects of region, length, age and maturation (reference region: Ireland)

\begin{tabular}{llllllll}
\hline Response & $\mathrm{N}$ & \%dev & AIC & Region & FA1 & Age & COW \\
\hline$\Sigma 18[\mathrm{PCB}]$ & 54 & 56.7 & 47.4 & France:,$+ \mathrm{P}<0.0001$ & $\mathrm{Df}=3.8, \mathrm{P}=0.0050$ &,$+ \mathrm{P}=0.0348$ & $\mathrm{Df}=1.8, \mathrm{P}=0.0318$ \\
& & & & Galicia:,$+ \mathrm{P}=0.0023$ & & & \\
$\Sigma 5[\mathrm{PBDE}]$ & 54 & 38.5 & 19.0 & & $\mathrm{Df}=1.8, \mathrm{P}=0.0130$ &,$+ \mathrm{P}=0.0206$ &,$- \mathrm{P}=0.0132$ \\
HBCDs & 47 & 78.8 & -22.2 & Galicia:,$- \mathrm{P}<0.0001$ & $\mathrm{Df}=2.2, \mathrm{P}=0.0094$ & $\mathrm{Df}=7.6, \mathrm{P}=0.0121$ &,$- \mathrm{P}=0.0104$ \\
\hline
\end{tabular}


Figure 1. Maps showing sampling locations for (a) harbour porpoises and (b) common dolphins. Circles indicate locations of stranded animals. Triangles indicate females in good condition that were sampled for blubber POP concentrations.

Fig. 2. Results of redundancy analysis (RDA) on persistent organic pollutant (POP) concentrations (excluding hexabromocyclododecane, HBCD) in blubber of female common dolphins: bi-plot of explanatory and response variables. $\mathrm{CdK}=$ cadmium concentration in kidney, COW = combined ovary weight, FA1, FA2 = scores on $1^{\text {st }}$ and $2^{\text {nd }}$ PCA axes in an ordination of fatty acid data, HgL = mercury concentration in liver, Hg_Se = ratio of mercury to selenium concentrations in liver, NCA = total number of corpora albicantia, $\operatorname{Prg}=$ pregnancy, Q2, Q3, Q4 $=2^{\text {nd }}, 3^{\text {rd }}$ and 4th quarters of the year (as compared to quarter 1 ), ZnL $=$ zinc concentration in liver. Results for France and Ireland are expressed in relation to those from Galicia.

Fig. 3. Results of RDA on POP concentrations (excluding HBCD) in blubber of female harbour porpoises: bi-plot of explanatory and response variables. Labels are as in Figure 3 except: DBT = dorsal blubber thickness. Results for Southern North Sea (SN Sea), France and Galicia are expressed in relation to those for Scotland.

Fig. 4. Illustration of generalised additive model (GAM) results for analysis of POP concentrations in common dolphin and porpoise blubber in relation to country, season, age, length, maturity and condition: (a) smoother for partial effect of combined ovary weight on summed polychlorinated biphenyl (PCB) concentrations in common dolphin blubber, (b) smoother for partial effect of combined ovary weight on HBCD concentration in common dolphin blubber. 
Fig. 1

(a)

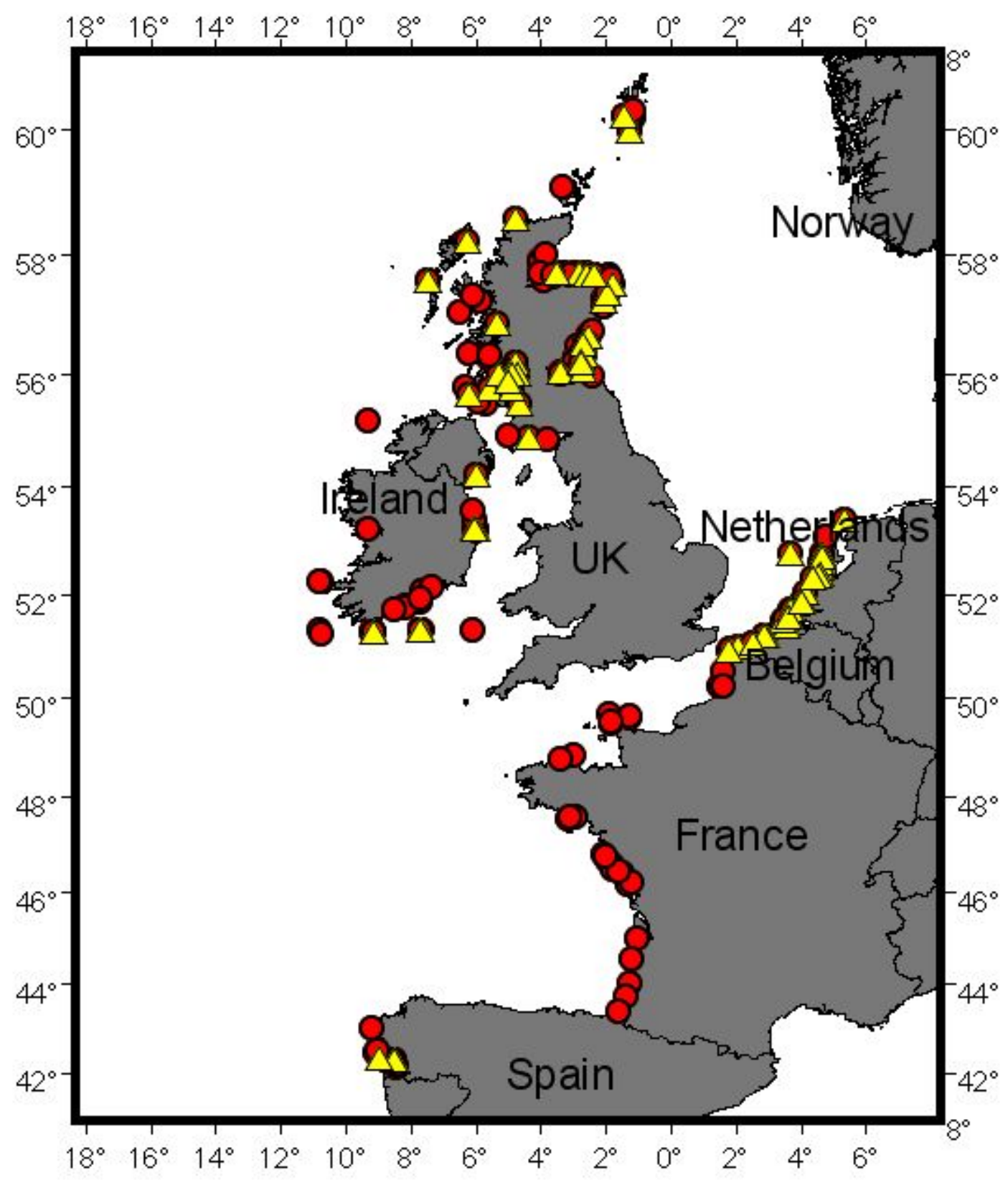


(b)

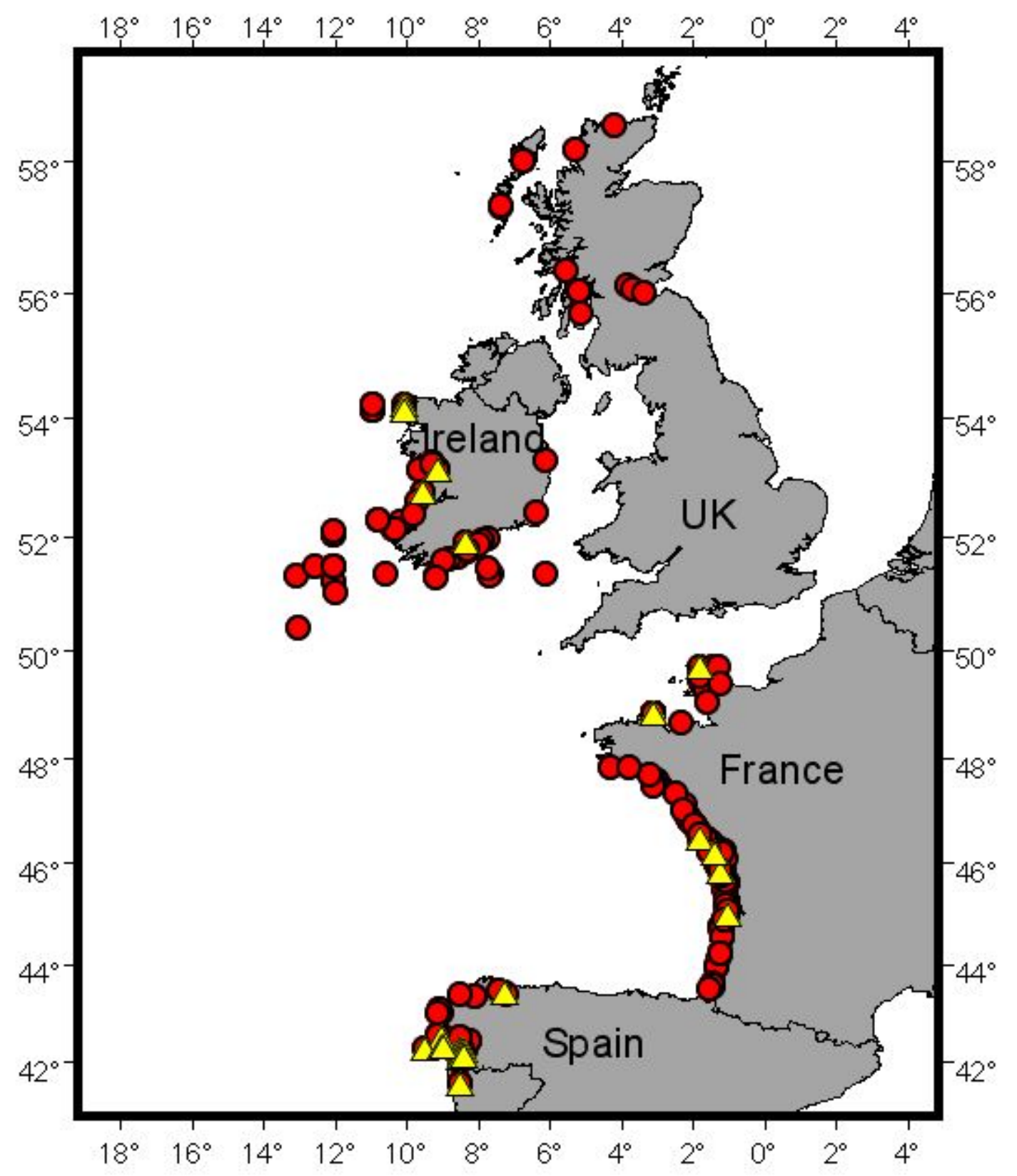


Fig. 2

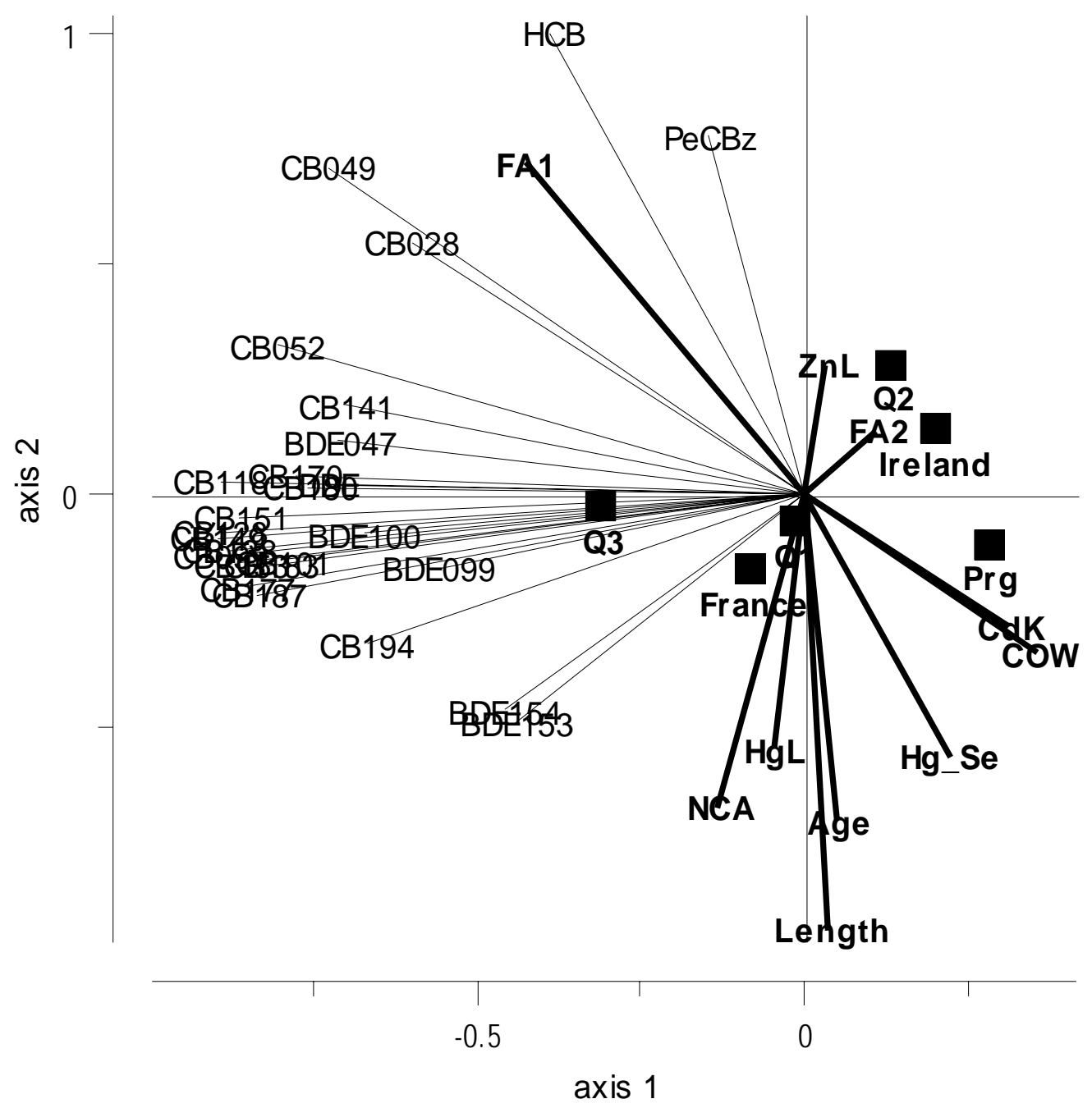


Fig. 3.

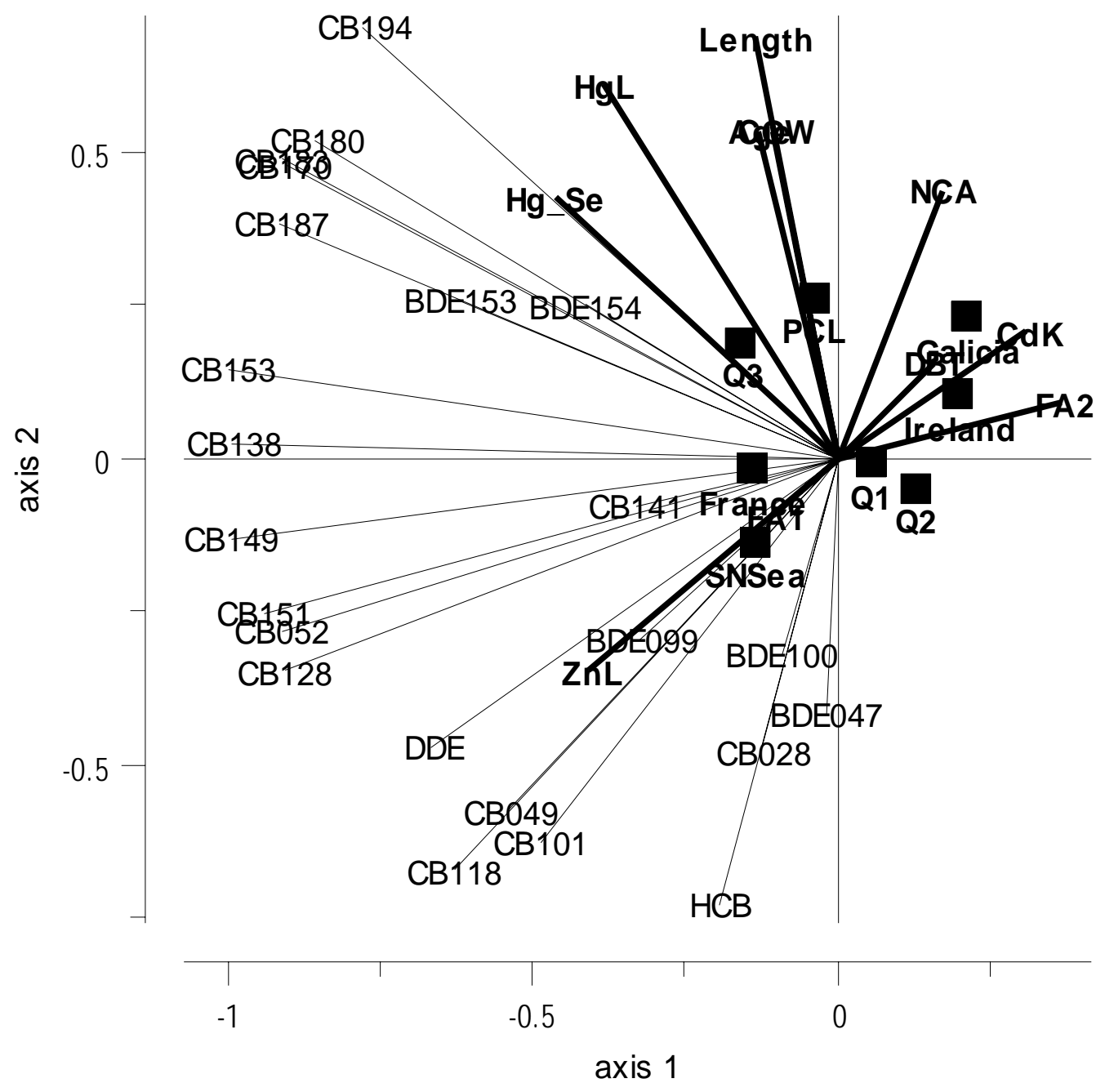


Fig. 4

(a)

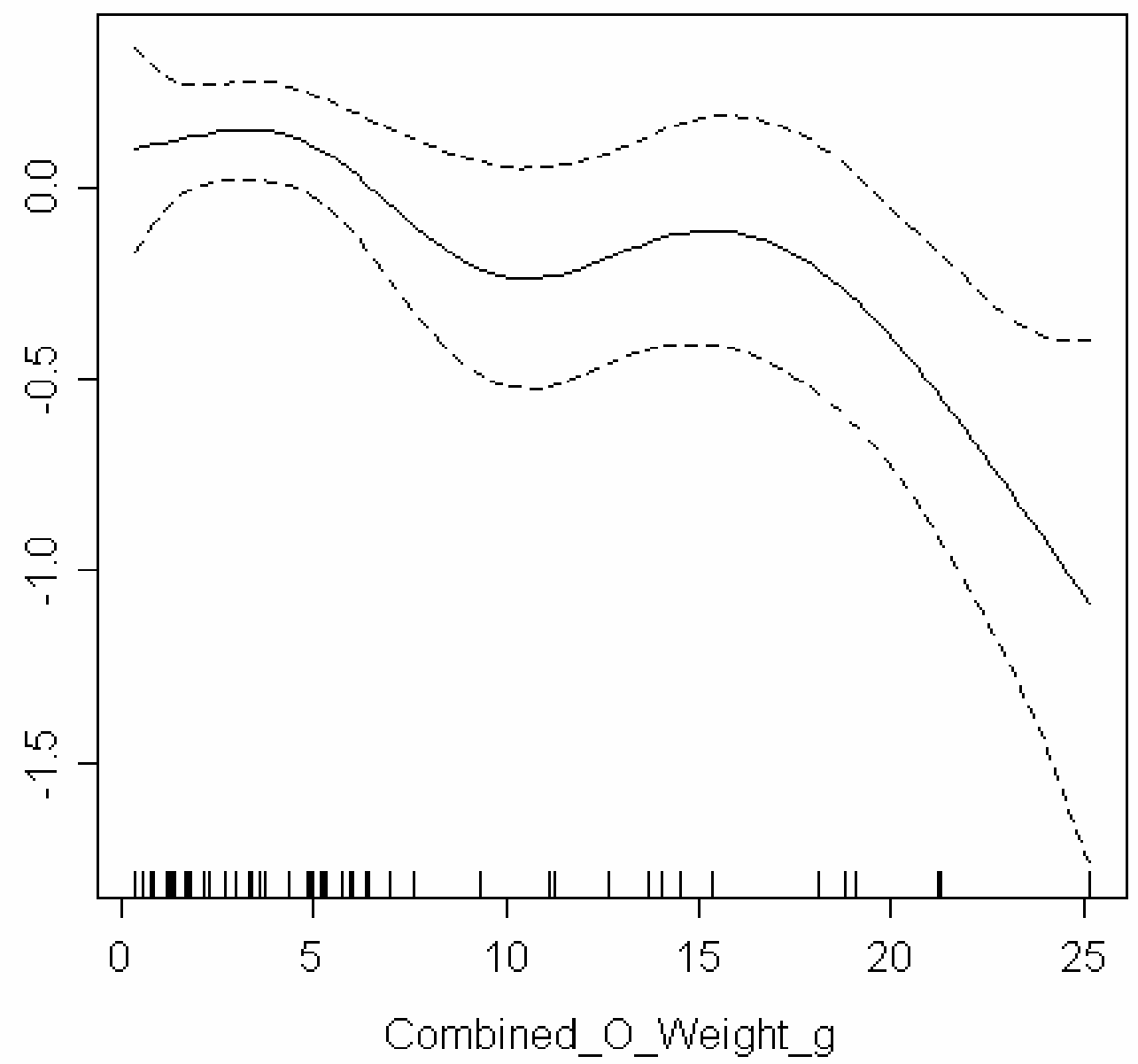


4(b)

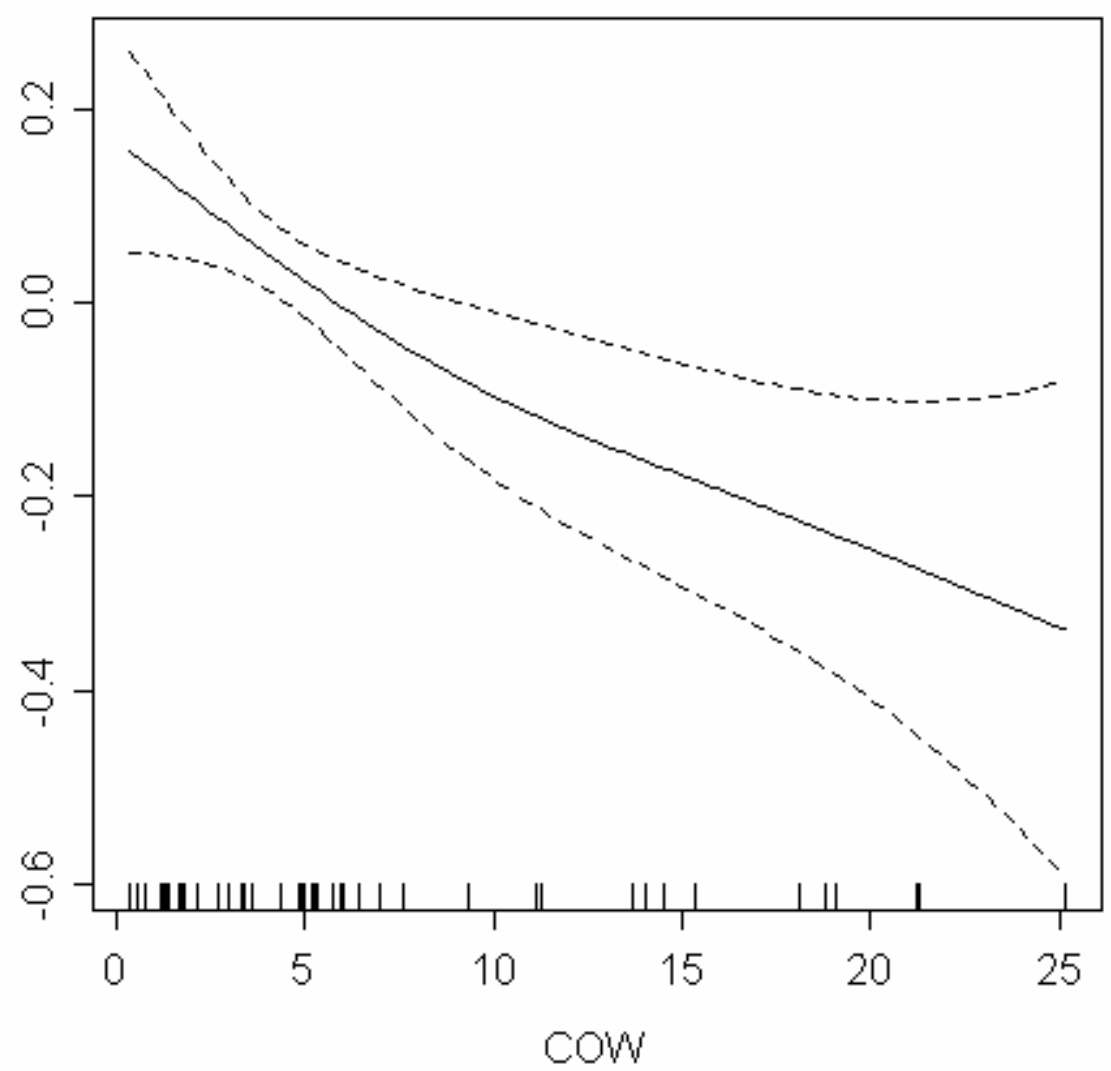

